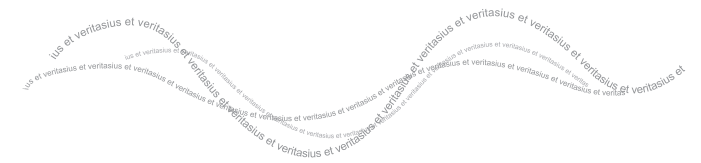

\title{
El concierto social como fórmula alternativa (y no contractual) para la gestión indirecta de los servicios sociales públicos(*)
}

\author{
The social agreement as an alternative (and non-contractual) formula for \\ the indirect management of public social services
}

\author{
Mónica Álvarez Fernández(**) \\ Universidad de Oviedo (Oviedo, España)
}

\begin{abstract}
Resumen: Las Directivas de la Unión Europea en materia de contratación han habilitado la posibilidad de que los Estados miembros puedan gestionar los servicios sociales públicos a través de fórmulas no contractuales. En España, esa posibilidad se ha concretado en los denominados conciertos sociales, regulados a través de las leyes de Servicios Sociales de las Comunidades Autónomas. Se trata de acuerdos a celebrar entre la Administración titular o responsable de los servicios y entidades de carácter privado, normalmente, sin ánimo de lucro. La naturaleza y el régimen jurídico de estos conciertos sociales, tal y como deriva de la regulación vigente, plantea, no obstante, algunas dudas que deberán ir resolviéndose a medida que su uso generalizado evidencie las fortalezas y debilidades de esta figura y la jurisprudencia resuelva al respecto.
\end{abstract}

Palabras clave: Servicios sociales públicos - Servicios sociales de interés general gestión indirecta - Gestión no contractual - Concierto social - Organización sin ánimo de lucro

\begin{abstract}
The procurement Directives have enabled member States of the European Union to manage public social services through a non-contractual formula. In Spain, this possibility has been realized in "social agreements", regulated through the Social Services Laws of the Autonomous Communities. These are agreements to be entered into between the Administration in charge of or responsible for the services and private entities, normally non-profit organizations. However, the nature and legal regime of these social agreements, as it results from the current regulation, raises some doubts. They should be resolved as their widespread use reveals the strengths and weaknesses of this figure and the case law resolves them.
\end{abstract}

Keywords: Public social services - Social services of general interest - Indirect management - Non-contractual management - Social agreement - Nonprofit organization

$\left(^{*}\right) \quad$ Nota del Editor: Este artículo fue recibido el 5 de febrero de 2021 y su publicación fue aprobada el 16 de marzo de 2021.

${ }^{* *}$ Profesora Titular de Derecho Administrativo de la Universidad de Oviedo. Miembro del grupo de investigación Derecho Administrativo (https://da.grupos.uniovi.es/). Of Counsel del Departamento de Regulatorio, Derecho Público, Urbanismo y Competencia en Ontier. ORCID: https://orcid.org/0000-0002-5093-1626. Correo electrónico: afmonica@uniovi.es. 


\section{Introducción}

Las últimas Directivas de la Unión Europea sobre contratación pública y sobre concesiones ${ }^{(1)}$ han dado una nueva vuelta de tuerca al marco jurídico de los contratos públicos en los distintos Estados miembros aunque, paradójicamente, también han impulsado la posibilidad de recurrir a instrumentos no contractuales en ámbitos que tradicionalmente han requerido la formalización de contratos en sentido estricto. Es el caso, en particular, de la prestación de determinados servicios de titularidad o responsabilidad pública y, por lo que ahora interesa, en concreto, de los servicios sociales.

La gestión de las prestaciones integrantes de los Sistemas Públicos de Servicios Sociales se había venido articulando hasta el cambio de paradigma actual, bien directamente por la propia Administración, a través de sus propios medios; bien indirectamente, mediante la celebración de contratos de gestión de servicios públicos en sus diversas modalidades ${ }^{(2)}$, fórmula contractual clásica en el ordenamiento jurídico español desde la Ley de Contratos del Estado de $1965^{(3)}$.

La nueva Ley 9/2017, de 8 de noviembre, de Contratos del Sector Público (en adelante, LCSP) truncó esta trayectoria suprimiendo el contrato de gestión de servicios aunque, a cambio, ha regulado dos vías con esa misma finalidad, la concesión de servicios y el contrato de servicios $^{(4)}$, dependiendo de que se traslade o no el riesgo operacional del contrato al adjudicatario $^{(5)}$.

No obstante, con ser importante este cambio, resultan aún más relevantes las nuevas posibilidades que la LCSP establece para flexibilizar la adjudicación y prestación tanto de las concesiones como de los contratos de servicios que se adjudiquen en el ámbito de los servicios sociales y satisfacer así más adecuadamente las necesidades a las que tales servicios se dirigen ${ }^{(6)}$.

Por una parte, y precisamente con la finalidad de garantizar la calidad, la continuidad, la accesibilidad, la asequibilidad, la disponibilidad y la exhaustividad de estos servicios ${ }^{(7)}$, así como las necesidades específicas de los usuarios a los que van

(1) Estas Directivas denominadas de cuarta generación son la Directiva 2014/24/UE, del Parlamento Europeo y del Consejo, de 26 de febrero de 2014, sobre contratación pública y por la que se deroga la Directiva 2004/18/CE, la Directiva 2014/23/UE, del Parlamento Europeo y del Consejo, de 26 de febrero de 2014, relativa a la adjudicación de contratos de concesión y, por último, la Directiva 2014/25/UE del Parlamento Europeo y del Consejo, de 26 de febrero de 2014, relativa a la contratación por entidades que operan en los sectores del agua, la energía, los transportes y los servicios postales y por la que se deroga la Directiva 2004/17/CE. Todas ellas publicadas en el DOUE L 94, de 28 de marzo de 2014.

(2) La concesión, la gestión interesada, la empresa de economía mixta y, principalmente, el concierto, habitual para la gestión indirecta de servicios sociales públicos.

(3) Decreto 923/1965, de 8 de abril, por el que se aprobó el texto articulado de la Ley de Contratos del Estado. Posteriormente, a partir de esta norma, ya bajo la influencia del Derecho comunitario, el contrato de gestión de servicios públicos se recogió en la Ley 13/1995, de 18 de mayo, de Contratos de las Administraciones Públicas, en el Real Decreto Legislativo 2/2000, de 16 de junio, por el que se aprobó el texto refundido de la Ley de Contratos de las Administraciones Públicas, en la Ley 30/2007, de 30 de octubre de Contratos del Sector Público y, finalmente, antes de su derogación por la actual normativa, en el Real Decreto Legislativo 3/2011, de 14 de noviembre, por el que se aprueba el texto refundido de la Ley de Contratos del Sector Público.

(4) De hecho, el contrato de servicios tiene una regulación específica en el artículo 312 LCSP cuando tiene por objeto prestaciones directas a favor de la ciudadanía.

(5) Véase sobre esta cuestión general Huergo, A. (2018). El riesgo operacional en la nueva Ley de Contratos del Sector Público. En M Vaquer, A. Moreno \& A. Descalzo (coord.), Estudios de Derecho Público en homenaje a Luciano Parejo Alfonso (pp. 1791-1832), Tirant lo Blanch; véase Hernández, F. (2018). La delimitación de los contratos públicos de servicios y de concesión de servicios. En J. Gimeno (dir.), Estudio sistemático de la Ley de Contratos del Sector Público (pp. 477-515). Thomson Reuters Aranzadi. En el ámbito de la prestación de servicios a las personas, véase Domínguez, M. (2019). Los contratos de prestación de servicios a las personas. Repensando las formas de gestión de los servicios sanitarios públicos tras las Directivas de contratos de 2014 y la Ley 9/2017 de Contratos del Sector Público. Revista General de Derecho Administrativo, 50. Asimismo, véase Garrido, A. (2020). Los servicios sociales en el s. XXI. Nuevas tipologías y nuevas formas de prestación. Aranzadi Thomson Reuters.

(6) El interés por promover la contratación "social" se pone de relieve en la propia Exposición de Motivos de la Ley que eleva a categoría de objetivo de la contratación pública la implementación de políticas tanto europeas como nacionales en materia social.

(7) En concreto esta posibilidad se concreta en relación con las concesiones de servicios y con los contratos de servicios de carácter social, sanitario o educativo del anexo IV, lo que incluye, en particular, los servicios consistentes en prestaciones sociales. Para un mejor conocimiento del alcance de los servicios a los que se refiere el Anexo puede verse el Reglamento (CE) 213/2008, de 28 de noviembre de 2007, que modifica el Reglamento (CE) 2195/2002, por el que se aprueba el Vocabulario común de contratos públicos (CPV), y las Directivas 2004/17/CE y 2004/18/CE del Parlamento Europeo y del Consejo sobre los procedimientos de los contratos públicos, en lo referente a la revisión del CPV. 
dirigidos, se exhorta a los órganos de contratación para que diseñen un régimen jurídico especial que alcance a todas las fases de estos contratos y que, sin perjuicio de la aplicabilidad de las disposiciones generales de la Ley, tenga en cuenta el contexto en que estos servicios se desenvuelven ${ }^{(8)}$. Se permite, pues, el establecimiento de una regulación particular para las concesiones y contratos de servicios que tienen por objeto servicios sociales, aunque se renuncia a establecer un marco normativo común para estos supuestos, remitiendo a lo que en cada caso estime conveniente el órgano de contratación ${ }^{(9)}$.

A su vez, la Ley permite reservar la adjudicación de contratos relativos a servicios sociales a determinados sujetos especiales. Por una parte, y como ya se venía recogiendo en normas anteriores a la vigente, a los Centros Especiales de Empleo de iniciativa social y a empresas de inserción ${ }^{(10)}$, a los que se reservarán necesariamente porcentajes mínimos del derecho a participar en procedimientos de adjudicación de determinados contratos o de su ejecución en el marco de programas de empleo protegido, siempre y cuando el porcentaje de trabajadores con discapacidad o en situación de exclusión social en estas entidades o programas sea el previsto en su normativa de referencia y, en todo caso, al menos del $30 \%{ }^{(11)}$.

Sin embargo, ahora se establece también la posibilidad de reservar el derecho a participar en los procedimientos de licitación de determinados contratos de servicios de carácter social(12) a algunas concretas organizaciones que cumplan todas las condiciones que contempla la Ley $^{(13)}$, organizaciones que no se identifican en sentido estricto con las denominadas entidades del tercer sector de acción social, sino que se extienden más allá de estas, también a las denominadas -entre nosotrosentidades de economía social(14).

(8) Así, por ejemplo, la propia disposición adicional cuadragésima séptima de la LCSP, que es la que contempla esta posibilidad, dispone que al establecer los criterios de adjudicación de estas concesiones y contratos, el órgano de contratación podrá referirlos a aspectos tales como: la experiencia del personal adscrito al contrato en la prestación de servicios dirigidos a sectores especialmente desfavorecidos o en la prestación de servicios de similar naturaleza, la reinversión de los beneficios obtenidos en la mejora de los servicios que presta o el establecimiento de mecanismos de participación de los usuarios y de información y orientación de los mismos.

(9) Así, véase Bernal, M. (2018). La contratación de los servicios a las personas. En E. Gamero \& I. Gallego (dir.), Tratado de Contratos del Sector Público (pp. 2841-2874). Tirant lo Blanch. Asimismo, véase Manent, L. \& Tenhaeff, S. (2018). Tipología de contratos (iii): los contratos para la gestión de servicios públicos. En J. Mestre \& L. Manent (dir.), Ley de Contratos del Sector Público: Ley 9/2017, de 8 de noviembre: aspectos novedosos (pp. 211-213). Tirant lo Blanch.

(10) Regulados respectivamente en el Real Decreto Legislativo $1 / 2013$, de 29 de noviembre, por el que se aprueba el texto refundido de la Ley General de Derechos de las personas con discapacidad y de su inclusión social, y en la Ley 44/2007, de 13 de diciembre, para la regulación del régimen de las empresas de inserción.

(11) Así se contempla en la disposición adicional cuarta de la LCSP.

(12) En concreto, los que se identifican en la disposición adicional cuadragésima octava de la LCSP expresamente con su código $\mathrm{CPV}$, entre los que se pueden mencionar, a modo de ejemplo, los servicios de asistencia social con y sin alojamiento, servicios de bienestar social proporcionados a discapacitados y a menores, servicios de centros de día, servicios sociales, servicios sociales administrativos o servicios prestados por asociaciones de carácter social y de carácter juvenil. Debe tenerse en cuenta, en todo caso, que la reserva no alcanza a todos, sino solo a algunos los contratos de servicios sociales del Anexo IV, a los que, sin embargo, sí se extiende la posibilidad de establecer un régimen jurídico especial.

(13) Estás condiciones se recogen en la disposición adicional cuadragésima octava de la LCSP y son las siguientes: (i) que su objetivo sea la realización de una misión de servicio público vinculada a la prestación de los servicios citados; (ii) que los beneficios se reinviertan con el fin de alcanzar el objetivo de la organización; (iii) en caso de que se distribuyan o redistribuyan beneficios, la distribución o redistribución deberá basarse en consideraciones de participación; (iv) que las estructuras de dirección o propiedad de la organización que ejecute el contrato se basen en la propiedad de los empleados o en principios de participación o exijan la participación activa de los empleados, los usuarios o las partes interesadas, y (v) que el poder adjudicador de que se trate no haya adjudicado a la organización un contrato para los servicios en cuestión con arreglo a lo previsto en la indicada disposición adicional en los tres años precedentes.

(14) Las primeras se regulan (cuando su ámbito de actuación es estatal o supera el territorio de una Comunidad Autónoma) en la Ley 43/2015, de 9 de octubre, del Tercer Sector de Acción Social. Las segundas, se rigen (todas las que actúen dentro del Estado) por la Ley 5/2011, de 29 de marzo, de Economía Social. Si bien entre estas últimas la mayoría carecen de ánimo de lucro, no necesariamente es así, por lo que, existe un matiz distintivo importante que puede determinar que no resulte posible extender a todas ellas en conjunto la calificación de entidades sin ánimo de lucro. La LCSP solo utiliza en una ocasión esta noción (entidades sin ánimo de lucro), en concreto, en el artículo 19.2.f) LCSP, para excluir de entre los contratos sujetos a regulación armonizada a los que teniendo por objeto determinados servicios de defensa civil, protección civil y prevención de riesgos laborales, sean prestados por organizaciones o asociaciones sin ánimo de lucro. 
A todos estos cambios ${ }^{(15)}$ deben sumarse la novedad apuntada más arriba, esto es, la posibilidad de que las Administraciones responsables de la prestación de servicios sociales puedan gestionarlos a través de terceros sin necesidad de celebrar un contrato articulando, en consecuencia, una nueva vía de colaboración público-privada no contractual en este ámbito ${ }^{(16)}$.

Si bien, no se trata de un mecanismo absolutamente nuevo en ciertos sectores de actividad administrativa, incluso del ámbito de los servicios a las personas ${ }^{(17)}$, sí lo es en el campo de los servicios sociales, $y$ han sido precisamente las Directivas de cuarta generación ( $y$, posteriormente, la LCSP) las que han determinado la reciente eclosión de normas reguladoras de los nuevos conciertos sociales aprobadas por las Comunidades Autónomas y de las que se deriva el nuevo régimen jurídico aplicable a este mecanismo.

\section{El presupuesto del concierto social: la prestación de servicios sociales como servicios públicos y como servicios de interés general}

El ámbito de nuestro análisis, los servicios sociales que tomamos como referencia, se concretan en el conjunto de medios personales, materiales y técnicos de todo tipo que confluyen en prestaciones concretas de carácter social y que tienen por objeto proporcionar una cobertura asistencial a personas, familias y grupos en situación de vulnerabilidad con la finalidad de promocionar su autonomía, favorecer su inclusión social, promover y proteger su desarrollo $y$, en definitiva, garantizarles una vida digna.

Cuando dicha actividad se planifica, organiza y se desarrolla como propia por la Administración adquiere la naturaleza de servicio público. Esto último se entiende como el resultado de una decisión administrativa o publicatio en relación con una determinada actividad que pasa a ser asumida por la Administración pública competente y que constituye el título de intervención sobre ella con el objetivo de satisfacer el interés general vinculado a la misma; ya sea en régimen de monopolio, o bien en concurrencia con los particulares ${ }^{(18)}$.

En el caso de los servicios sociales resulta aplicable, sin duda, esta concepción de

(15) Pueden mencionarse igualmente otras previsiones que inciden en la singularidad y especialidad de la contratación en el ámbito de los servicios sociales como, por ejemplo, la elevación del umbral económico para la sujeción a regulación armonizada de los contratos que se celebren con este objeto a 750.000 euros o, tratándose de una concesión de servicios, a 5.350 .000 euros [artículos 22.1.c) y 20.1 LCSP]. También la posibilidad de que se establezca un plazo de duración superior a los cinco años establecidos para los contratos de servicios "cuando ello fuera necesario para la continuidad de aquellos tratamientos a los usuarios en los que el cambio del prestador pudiera repercutir negativamente" (artículo 29.4 LCSP), o, igualmente, que sea necesario tener en cuenta una pluralidad de criterios de adjudicación en los contratos de prestación de servicios sociales si fomentan la integración social de personas desfavorecidas o miembros de grupos vulnerables entre las personas asignadas a la ejecución del contrato, promueven el empleo de personas con dificultades particulares de inserción en el mercado laboral o cuando se trate de los contratos de servicios sociales de los previstos en la disposición adicional cuadragésima octava [artículo 145.3.g) LCSP].

(16) Si bien, excede del objeto de este trabajo, debe apuntarse que en las normas más recientes dictadas por las Comunidades Autónomas en el marco de las competencias que todas ellas ostentan en materia de servicios sociales, junto al concierto social se contempla también la posibilidad de gestión de servicios sociales del Sistema Público correspondiente mediante la suscripción de convenios con entidades de iniciativa social sin ánimo de lucro en los casos en los que la actividad o servicio de que se trate presente singularidades, la prestación sea urgente, o bien tenga carácter experimental o innovador. Véase, a modo de ejemplo, lo dispuesto en el artículo 110 de la Ley 9/2016 de Andalucía, en el artículo 25 nonies de la Ley 3/2003 de la Región de Murcia o en el artículo 69 de la Ley vasca 12/2008. Asimismo, el artículo 21 de la Ley 12/2018 de las Islas Baleares se refiere a la cooperación directa, que deberá justificarse en la mejor eficiencia de la prestación, en la eficacia presupuestaria y en la no distorsión indebida de la competencia. En relación con estos Convenios (y la ausencia de regulación precisa en la mayoría de los casos) podrían apuntarse la gran mayoría de las dudas y cautelas que se ponen de manifiesto en este trabajo respecto al concierto social. Deben diferenciarse en todo caso, de los supuestos de acuerdos directos de acción concertada que se prevén en algunas normas autonómicas.

(17) La idea de "servicios a las personas" a la que se refieren las Directivas comunitarias incluye no solo a los servicios sociales, sino también a los servicios sanitarios y educativos. Para estos últimos ya se había previsto a través de sus normas específicas y mucho antes de la consagración por las Directivas comunitarias de la "acción concertada" en el ámbito estrictamente social, la posibilidad de establecer conciertos por vía convencional. En el ámbito sanitario en el que ha sido habitual el recurso a los conciertos, los artículos 66 y 67 de la Ley 14/1986, de 25 de abril, General de Sanidad y las normas autonómicas dictadas en desarrollo de la regulación básica en la materia, regulan el régimen de convenios singulares que permiten la celebración de conciertos especiales (junto con los conciertos ordinarios regulados en el artículo 90 de la misma Ley). Los conciertos educativos, por su parte, se configuran como instrumentos en virtud de los cuales los centros privados se sostienen con fondos públicos para impartir los niveles de enseñanza obligatoria en régimen de gratuidad. Tales instrumentos adoptan la forma de convenios de acuerdo con lo establecido en el artículo 116 de la Orgánica 2/2006, de 3 de mayo, de Educación y las normas de desarrollo autonómicas.

(18) Nos encontraríamos aquí con las dos manifestaciones del servicio público más tradicionales. Por una parte, el servicio público 
servicio público, toda vez que la consecución de los objetivos del Estado Social y, por tanto, la efectividad de un nivel de bienestar aceptable respecto a necesidades sentidas como básicas por la comunidad, requieren una toma de posición de la Administración dirigida a asegurar la disponibilidad de los servicios sociales y el acceso a los mismos así como su cumplimiento efectivo, lo que conlleva su gestión y provisión en un régimen de Derecho público exorbitante. Ahora bien, como ha ocurrido tradicionalmente en este sector, no se constituye un monopolio de iure en la prestación, sino que la participación del sector privado, y especialmente de las entidades de iniciativa social, como se analizará más adelante, resulta una característica básica en el ámbito de los servicios sociales.

La actividad "publificada" de competencia administrativa se articula a través de los Sistemas Públicos de Servicios Sociales, que se configuran como la estructura que sustenta todo el conjunto de servicios sociales de titularidad y responsabilidad administrativa ${ }^{(19)}$, integrando, por una parte, los recursos, prestaciones, actividades, programas, proyectos y equipamientos públicos $\mathrm{y}$, por otra, los de carácter privado con los que las Administraciones contraten, concierten o celebren acuerdos o convenios de colaboración ${ }^{(20)}$, con el objetivo común de hacer frente a las situaciones de necesidad y vulnerabilidad ${ }^{(21)}$.

Ahora bien, como se adelantó, la intervención privada en el ámbito de la acción social tiene una importancia destacada más allá de las redes públicas de servicios sociales, admitiéndose sin restricción alguna, como no podía ser de otra manera, no solo como fuente de prestaciones sociales en el marco de los principios de solidaridad y cohesión social, sino también como ámbito generador de empleo y riqueza. La actividad desplegada por este sector privado se integraría en lo que se han denominado

que conlleva un monopolio de la Administración y que se justifica sobre lo establecido en el artículo 128.2 CE. Se trataría de un concepto estricto o restringido de servicio público, frente a una modalidad distinta en la que la actividad prestacional asumida por la Administración coexiste con la iniciativa de los particulares, si bien, manteniendo el resto de los caracteres propios del servicio público. Asimismo, recomendamos la lectura un estudio sobre las distintas concepciones del servicio público, véase Álvarez, M. (2004). El abastecimiento de agua en España (pp. 257-291). Editorial Civitas. En esta literatura, se diferencia entre la publicatio estricta e intensa y la publicatio laxa o débil. Respecto del distinto alcance de las concepciones de servicio público, también véase Gómez-Ferrer, R. (1973). El régimen general de los Centros privados de enseñanza. Revista de Administración Pública, 70, 7-27; véase Souvirón, J. (1998). La actividad de la Administración y el servicio público (p. 499). Comares. También, véase Chinchilla, M. (1991). El servicio público ¿una amenaza o una garantía para los derechos fundamentales? Reflexiones sobre el caso de la televisión. En S. Retortillo (coord.), Estudios sobre la Constitución Española. Homenaje al Profesor Eduardo García de Enterría (pp. 943-972). Civitas. Véase De La Cuétara, J. (1993). La actividad de la Administración (p. 133). Tecnos. En relación con el ámbito de acción social, véase Tornos, J. \& Galán, A. (2007). La configuración de los servicios sociales como servicio público. Derecho subjetivo de los ciudadanos a la prestación del servicio (pp. 19-20). Ministerio de Trabajo y Asuntos Sociales. Véase Moreno, M. (2002). Régimen jurídico de la asistencia social (pp. 114-115). Ministerio de Trabajo y Asuntos Sociales. Asimismo, véase Beltrán, J. (1992). El régimen jurídico de la acción social pública (p. 137). Instituto Vasco de Administración Pública. También véase Vaquer M. (2005). Los problemas de la contraposición entre económico y social en la doctrina europea de los servicios de interés general. Revista General de Derecho Administrativo, 8. Muy anteriormente, véase Martín, R. (1967). Guía de actividades públicas asistenciales. La asistencia social como servicio público (pp. 55-59). Ministerio de la Gobernación.

(19) Sobre los caracteres de estos sistemas jurídicos véase Alonso, J. \& Alemán, C. (2020). El sistema de servicios sociales. Nuevas tendencias en España (p. 68). Tirant lo Blanch. Asimismo, véase Alonso, J. \& Gonzalo, B. (2000). La asistencia social y los servicios sociales en España (2. ${ }^{a}$ ed.), Boletín Oficial del Estado; véase Alemán, C. \& Alonso, J. (2011). Los sistemas de servicios sociales en las Leyes autonómicas de servicios sociales. Revista General de Derecho Administrativo, 27. Finalmente, véase Malaret, E. (2002). Administración pública y servicios públicos: la creación de una red de servicios sociales a los ancianos en la transformación del Estado de Bienestar. En Los servicios sociales de atención a la tercera edad: el caso de Cataluña (pp. 265-332). Tirant lo Blanch Valencia (p. 239).

(20) El complemento a esta organización son las Carteras o Catálogos de servicios sociales que se contemplan en las Leyes de Servicios Sociales más actuales y en los que se identifican el conjunto de prestaciones (técnicas, económicas y materiales) garantizadas desde los Sistemas Públicos de Servicios Sociales. Además de los anteriores puede preverse otros servicios que, sin embargo, no quedan garantizados.

(21) A ello deberían sumarse las prestaciones de los Sistemas de Autonomía y Atención a la Dependencia que se han integrado en los Sistemas Públicos de Servicios Sociales autonómicos, tal y como prevé el artículo 16.1 de la Ley 39/2006, de 14 de diciembre, de Promoción de la Autonomía Personal y Atención a las personas en situación de dependencia. Véase al respecto, Palomar, A. (2008). El sistema integral de promoción de la autonomía personal y atención a las personas en situación de dependencia. Competencias. En A. Sempere \& P. Charro (coords.), Comentario sistemático a la Ley de Dependencia. Ley 39/2006, de 14 de diciembre, de Promoción de la Autonomía Personal y Atención a las Personas en Situación de Dependencia y normas autonómicas. Cizur Menor (Navarra): Thomson-Aranzadi (p. 249). Finalmente, véase De Palma, A. (2009). Los servicios sociales en Cataluña como marco de atención a las situaciones de dependencia. En V. Aguado (coord.), Servicios Sociales, dependencia y derechos de la ciudadanía. Atelier Barcelona (p. 127). 
Sistemas de Servicios Sociales, entendidos como ámbito más amplio y genérico que incluiría a todos los servicios sociales "regulados"(22) dispensados en un territorio.

Desde esta última perspectiva, la concepción tradicional del servicio público, en su significado objetivo o material, al que hemos aludido, se ampliaría con una acepción funcional del mismo, que se identifica con una versión del servicio público entendido como finalidad social o asistencial a satisfacer, que puede cumplirse, por tanto, no solo desde instancias públicas, sino también en un marco estrictamente privado aunque intervenido ${ }^{(23)}$. La Administración asumiría entonces potestades de planificación, autorización y, en su caso, acreditación e inspección, pero también de colaboración y financiación.
Esta visión amplia y funcional del servicio público es la que se acoge en el Derecho comunitario y se concreta en el concepto de servicio de interés general ${ }^{(24)} 0$, más precisamente, en relación con la actividad que se analiza, de servicios sociales de interés general ${ }^{(25)}$ que se corresponden con los servicios esenciales prestados directamente a la persona, los cuales se desempeñan un cometido preventivo y de cohesión e inclusión social(26).

Ahora bien, este nuevo concepto(27) no se dirige a definir los contornos de una nueva institución jurídica a escala europea, sino

(22) Esto es, tanto las prestaciones que integran las redes públicas de servicios sociales como todos aquellos recursos prestados por la iniciativa privada (con o sin ánimo de lucro) que, aun cuando no se asuman por la Administración deben cumplir unos requisitos básicos vinculados a la calidad en su prestación y a las garantías de los usuarios, han de quedar sometidos a un régimen de previa autorización y registro.

(23) Véase Rodríguez de Santiago, J. (2007). La Administración del Estado Social (p. 69). Marcial Pons. En esta fuente, se contrapone así la responsabilidad estatal plena o de completo cumplimiento a la responsabilidad estatal de regulación del marco normativo colocando entre uno y otro extremo diversos tipos de responsabilidad que se refieren al tipo de función que realiza el Estado y a la intensidad de la vinculación entre el sujeto público y la actividad. Véase Tornos, J. \& Galán, A. (2007). La configuración de los servicios sociales como servicio público. Derecho subjetivo de los ciudadanos a la prestación del servicio (p. 14). Ministerio de Trabajo y Asuntos Sociales. Asimismo, de acuerdo con Gimeno, J. (2018, p. 14), se parte de la idea de un Estado garante de servicios públicos de calidad, en el que lo esencial es la regularidad, continuidad y neutralidad de los mismos y no tanto quien los presta.

(24) Sobre el concepto de servicio de interés general, véase, además de los documentos que se citan aquí, en la doctrina, entre otros muchos trabajos, los de Laguna de Paz, J. (2007). Servicios de interés económico general (p. 37). Civitas-Thomson-Reuters. Asimismo, véase Díez-Picazo, L. (2009). Los servicios de interés económico general en el ordenamiento comunitario. En Muñoz Machado, S. \& Esteve Parado, J., (dirs.), Derecho de la regulación económica. I. Fundamentos e instituciones de la regulación (p. 409). Iustel.; véase Parejo, L. (2004), Servicios públicos y servicios de interés general: la renovada actualidad de los primeros. Revista de Derecho de la Unión Europea, 7, 56; véase Malaret i García, E. (2003) Servicio público, actividad económica y competencia. ¿Presenta especificidades la esfera local?, Revista de Estudios de la Administración Local, 291, 579; Muñoz, S. (1998), Servicio público y mercado. I Los fundamentos (p. 225). Civitas; y, en particular, Vaquer, M. (2010). De nuevo sobre la "doctrina europea de los servicios de interés general: los problemas para definir la familia de los servicios sociales" y su aplicación en materia de vivienda. Revista General de Derecho Administrativo, 25; y Aguado i Cudolà, V. (2012). El régimen jurídico de las prestaciones de los servicios sociales. En A. Ezquerra (coord.), El marco jurídico de los servicios sociales en España (p. 57). Atelier.

(25) Ahora bien, tal y como establece la Comunicación de la Comisión "Aplicación del programa comunitario de Lisboa. Servicios sociales de interés general en la Unión Europea", COM (2006) 177 final, de 26 de abril, de 2006: 4, los servicios sociales de interés general "no constituyen una categoría jurídica diferenciada dentro de los servicios de interés general", pero sí que se les reconoce un "lugar específico como pilares de la sociedad y de la economía europeas", de la denominada economía social, resultando indispensable para lograr la cohesión social, económica y territorial en el ámbito de la UE. La Unión Europea acoge, en este sentido, los postulados del Estado Social. De hecho, los Tratados señalan como objetivos a alcanzar los de progreso y protección sociales, cohesión, solidaridad y lucha contra la exclusión social, todo ello en el marco de una "economía social de mercado" (artículo 3 TUE). La Resolución del Parlamento Europeo, de 5 de julio de 2011, "Sobre el futuro de los servicios sociales de interés general" (2009/2222(INI)), considera que tales servicios constituyen un "pilar esencial del modelo social europeo y como base para una buena calidad de vida y para la consecución de los objetivos económicos, de empleo y sociales de la UE”. El artículo 9 TFUE prevé que en el diseño y ejecución de las competencias asumidas por la Unión se tomen en consideración de todas las exigencias vinculadas a la consecución de una protección social adecuada. Por su parte, la Carta de Derechos Fundamentales de la Unión Europea enumera, bajo el epígrafe "Solidaridad", una serie de derechos sociales vinculados a la protección de trabajadores, familias, jóvenes y niños, a la salud, a la seguridad social y a la ayuda social.

(26) En este sentido, la Comunicación de la Comisión COM(2011) 900 final, de 20 de diciembre de 2011, "Un marco de calidad para los servicios de interés general en Europa": 4. Por su parte, la Comunicación COM(2006) 177 final: 4, incluía entre los servicios esenciales prestados directamente a la persona las ayudas para afrontar retos inmediatos de la vida o crisis, las actividades destinadas a asegurar que las personas posean las competencias necesarias para su inserción completa en la sociedad y, en particular, en el mercado laboral, las actividades destinadas a garantizar la inclusión de las personas con necesidades a largo plazo debidas a una discapacidad o a un problema de salud, así como la vivienda social.

(27) El Protocolo № 26 "Sobre los servicios de interés general", adjunto al Tratado de Lisboa, introdujo, por primera vez la noción de servicios de interés general de carácter no económico en el Derecho comunitario originario. Hasta entonces el único concepto que se había manejado en los Tratados era el de servicios económicos de interés general. 
fundamentalmente a acotar el ámbito de aplicación de las normas de Derecho comunitario y, en particular, las reglas relativas a competencia y mercado interior, así como las relativas a la contratación pública y, en definitiva, a condicionar el régimen jurídico aplicable a las prestaciones sociales. Por lo tanto, resulta básico identificar, en primer lugar, cuáles son los servicios sociales de interés general y, dentro de ellos, los de carácter económico y no económico.

La distinción aludida deriva del tipo de actividad y, en particular, de la forma en que esta se presta, organiza y financia(28) independientemente de cuál sea su naturaleza y de quién preste efectivamente el servicio. Sobre esta base, la jurisprudencia del Tribunal de Justicia Europeo ha venido considerando como no económicas actividades de carácter puramente asistencial, dirigidas estrictamente a la protección social de personas, familias o grupos vulnerables, gestionadas directa o indirectamente por la Administración y financiadas con cargo a los presupuestos públicos ${ }^{(29)}$. Se trataría de servicios directamente vinculados a la satisfacción de los principios de cohesión social y solidaridad(30). En cambio, serían actividades económicas todas aquéllas que consisten en la oferta en un mercado a cambio de una remuneración que actúa a modo de contrapartida por la prestación, y ello aun cuando tal remuneración no corra a cargo de los beneficiarios o usuarios del servicio, e incluso en los casos en que dichas actividades revistan los caracteres propios de una prestación social y se desarrollen por una entidad pública o por una organización sin ánimo de lucro $^{(31)}$.

Trasladando lo anterior a nuestro ordenamiento jurídico español, y sin poder realizar una identificación nítida, podrían considerarse, no obstante, como servicios sociales de carácter no económico los que en el ámbito propio de los Sistemas Públicos de Servicios Sociales autonómicos cubren una necesidad de carácter vital, entendida ésta como la exigencia de contar con unas condiciones de existencia dignas en sus diferentes vertientes ${ }^{(32)}$. Pero además, y junto

(28) Tal y como ha establecido la Comunicación de la Comisión - COM (2007) 725 final, de 20 de noviembre de 2007, "Servicios de interés general, incluidos los sociales: un nuevo compromiso europeo", que acompaña a la Comunicación "Un mercado único para la Europa del siglo veintiuno" (p. 5), no resulta fácil delimitar esa diferencia a priori, sino que resulta necesario un análisis caso por caso. Una crítica sobre esta indefinición en Vaquer (2010, pp. 18-19). Laguna de Paz, J. (2016, p. 22), señala que no hay servicios que por naturaleza pertenezcan a una u otra categoría, sino que "todo depende de su régimen jurídico". Para Domínguez, M. (2019, p. 12), la diferenciación entre servicios de interés económico general y servicios no económicos de interés general es "dinámica y evolutiva, dado que la existencia o no de un mercado en un determinado sector dependerá de la evolución tecnológica, económica y social".

(29) Véase la STJCE de 27 de septiembre de 1988, asunto C- 263/86, Humbel (ECLI:EU:C:1988:451), apartados 16 a 20 en relación con las prestaciones del sistema nacional de educación. El Tribunal advierte que no existe contraprestación de los usuarios, pues cuando el Estado establece y mantiene el servicio de educación no se propone realizar actividades remuneradas, sino que cumple, respecto a la población, objetivos del ámbito social, cultural y educativo. En el mismo sentido la Sentencia de 7 de diciembre de 1993, asunto C-109/92, Wirth (ECLI:EU:C:1993:916), apartados 15 y 16. Pero incluso en el caso de que hubiera una contribución económica por parte de los beneficiarios del servicio, dado que su importe sería siempre inferior al precio del servicio y no se dirigiría, en sentido estricto, a pagar la prestación que se recibe, no podría identificarse como una remuneración frente al servicio.

(30) La STJCE de 17 de febrero de 1993, asuntos C-159/91 y C-160/91, Poucet y Pistre (ECLI:EU:C:1993:63), apartado 18, considera que unas entidades gestoras de un seguro de enfermedad y los organismos que participan en la gestión del servicio público de Seguridad Social desempeñan una actividad no económica, por basarse en el principio de solidaridad nacional, carecer de toda finalidad lucrativa y, además, por resultar las prestaciones independientes de la cuantía de las cotizaciones. En el mismo sentido también la STJCE de 22 de enero de 2002, asunto C-218/00, Cisal (ECLI:EU:C:2002:36), apartados 44 a 46 y la STJCE de 17 de junio de 1997, asunto C-70/95, Sodemare (ECLI:EU:C:1997:301), apartado 29.

(31) En este sentido la STJCE de 12 de septiembre de 2000, asuntos acumulados C-180/98 a C-184/98, Pavlov y otros (ECLI:EU:C:2000:428), apartados 117 y 118 y la STJCE de 22 de enero de 2002, ya citada, apartado 37. Por su parte, la STJCE de 25 de octubre de 2001, asunto C-475/99, Glöckner ECLI:EU:C:2001:577), apartado 20, considera como actividad económica el servicio de transporte urgente y de transporte de enfermos a cargo de una organización que carece de ánimo de lucro. Por su parte, la Comisión incluye en esta categoría también aquellos servicios sociales que se desarrollan en "centros de acción social" que ofrecen servicios a las personas mayores y a los discapacitados. Así lo recoge el apartado 33 del Documento SEC (2013) 53 final/2, de 29 abril de 2013, "Guía relativa a la aplicación de las normas de la Unión Europea en materia de ayudas estatales, contratación pública y de mercado interior a los servicios de interés económico general y, en particular, a los servicios sociales de interés general" (p. 34).

(32) Urgencia o exclusión social, riesgo o desamparo de menores y adultos, inseguridad, discapacidad o dependencia en todas sus manifestaciones, violencia doméstica o de género, etc. Al respecto Tornos \& Galán (2007, p. 24), véase Vaquer (2010, p. 12), la diferencia entre servicios sociales de carácter económico y los de carácter no económico refiriéndose a las viviendas sociales. Como ya se indicó, las Leyes de Servicios Sociales autonómicas incorporan como principio básico informador de su actuación el de la responsabilidad pública, que se traduce, por lo que aquí interesa, en la asunción, por parte de los poderes públicos, de la obligación de atender los problemas sociales movilizando para ello los recursos financieros, humanos y técnicos necesarios. 
a lo anterior, esas necesidades vitales de que se trata no deben poder ser satisfechas autónomamente por sus beneficiarios por falta de condiciones o de medios, procediendo, en consecuencia, su provisión por terceros (esencialmente, por la Administración o por entidades de iniciativa social), pero al margen de una remuneración o de cualquier otro interés lucrativo, pues aún en el caso de que los destinatarios lleguen a contribuir a la prestación, tal contribución sería insuficiente para cubrir su coste ${ }^{(33)}$, encajando, por lo tanto, en un engranaje que responde prioritariamente al principio de solidaridad ${ }^{(34)}$.

Todos los demás servicios sociales distintos de los anteriores, que en la práctica serían la mayoría, se considerarán actividades económicas en sentido estricto. Se ajustarían a esta categoría todos aquellos servicios sociales dirigidos a proporcionar a sus destinatarios bienestar ante las situaciones de vulnerabilidad en que se encuentren. Tendrían este carácter, en todo caso, cuando la prestación que se ofrece, bien desde instancias públicas, bien desde el sector privado (lucrativo o no lucrativo), va dirigida a coadyuvar a los medios y recursos de los que el propio beneficiario dispone para hacer frente a su situación o, por supuesto, en los casos en que la prestación se obtiene a cambio de una remuneración.

Como se adelantó esta distinción resulta importante a efectos de determinar la aplicabilidad del Derecho comunitario $y$, por ende, también, aunque en muy inferior medida, del ordenamiento jurídico interno. Así, los servicios sociales económicos, aun cuando se limita la acción de la Unión Europea reconociéndose a las Administraciones Públicas, en sus distintos niveles, una amplia discrecionalidad para su prestación, gestión y organización ${ }^{(35)}$, quedan sometidos, por una parte, a las normas sobre competencia en los términos del artículo 106 del Tratado de Funcionamiento de la Unión Europea (en adelante, TFUE) ${ }^{(36)} y$, por otra parte, a las normas sobre mercado interior de acuerdo con lo previsto en los artículos 49 y 56 TFUE, lo que no impide, a su vez, que deban ser objeto de determinadas exigencias destinadas a regular el mercado como son, por ejemplo, las obligaciones de autorización o registro de las prestaciones, servicios o centros correspondientes $\mathrm{y}$, todo en ello, en atención a las "razones imperiosas de interés general" en que se constituyen los objetivos de política

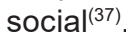

Además, estos servicios sociales quedan sujetos a las normas de contratación, ahora bien, dado que carecen normalmente de interés transfronterizo su sumisión a las Directivas de contratos resulta limitada, primero, por la necesidad de que superen los umbrales previstos en las normas comunitarias, más elevados que los de otros servicios y, en todo caso, cuando los superen, su adjudicación se realizará con arreglo a un régimen más simplificado e incluso, específico, con reserva a determinadas entidades, de acuerdo con lo que se ha señalado más arriba.

Por su parte, los servicios sociales no económicos quedan excluidos de la aplicación de las normas generales sobre competencia y ayudas de Estado y también de las vinculadas a la libre prestación de servicios y de establecimiento, de acuerdo, en este último caso, con lo previsto en la Directiva 2006/123/CE, siempre y cuando se gestionen directamente por la Administración o indirectamente por encargo de esta y, en su caso, por una entidad de iniciativa social sin ánimo de lucro ${ }^{(38)}$. También se excluye del ámbito de las Directivas en materia de contratos.

(33) La remuneración de esas prestaciones procederá básicamente, en el caso de las prestadas por la Administración, de las partidas asignadas en los presupuestos, y obtenidas de la recaudación impositiva de los ciudadanos y, en el caso de las entidades de iniciativa social, de las donaciones o, en su caso, de las subvenciones que puedan recibirse de las instituciones públicas.

(34) Véase Míguez, L. (2012). La transformación del régimen jurídico de los servicios sociales. Revista Española de Derecho Administrativo, $153,41-42$.

(35) Artículo 1 del Protocolo $N^{\circ} 26$. Será necesario, sin embargo, alcanzar una serie de objetivos como son los de cercanía al usuario, alto nivel de calidad, seguridad y accesibilidad económica, igualdad de trato y acceso universal.

(36) Salvo que la aplicación de tales normas impida, de hecho o de derecho y de manera justificada, el cumplimiento de la finalidad de interés general que aquellos servicios tienen asignada, en cuyo caso también se excepcionaría esa aplicación. En este sentido, la STJCE en el asunto Glöckner, ya citada, apartado 61.

(37) Esos objetivos se identifican claramente en la Comunicación COM (2007) 725 final: 7. Por su parte, la Directiva 2006/123/CE justifica esos regímenes de autorización en su artículo 9. Debe recordarse que las prestaciones de que se trata se vinculan a la dignidad humana, a la vida o a la salud y, por lo tanto, una supervisión a posteriori de la actividad desplegada por un prestador podría resultar insuficiente para evitar daños y perjuicios a los beneficiarios de los servicios. Se justifica también en el apartado 6.5 del Documento SEC (2010) 1545 final: 86, ya citado, que recoge la Guía para la aplicación a los servicios sociales de interés general de las reglas sobre mercado interior y competencia.

(38) La Directiva 2006/123/CE, de 12 de diciembre de 2006, relativa a los servicios en el mercado interior, se refiere a los servicios no económicos de interés general en el artículo 2.2.a) y, específicamente, en el apartado 2.2.j) excluye del ámbito de aplicación de 
No es el caso de nuestro Derecho interno, pues la LCSP, con carácter general se aplica a cualquier contrato público celebrado por una Administración Pública que tenga por objeto la prestación por un tercero de servicios sociales públicos, cualquiera que sea la naturaleza o carácter de éstos. Todo ello sin perjuicio de la incorporación del régimen de contratación más laxo que se establece para la contratación de estos servicios en algunos casos y, por supuesto, del reconocimiento de la posibilidad de recurrir a fórmulas no contractuales, vía por la que se ha articulado el concierto social que se analiza aquí.

\section{El contexto jurídico del concierto social}

Los servicios sociales identificados, por su propia naturaleza y por esa limitada dimensión transfronteriza indicada, presentan unos perfiles específicos y singulares que determinan la forma de su prestación, vinculada íntimamente a las distintas circunstancias administrativas, organizativas y culturales de cada Estado miembro. Es por ello que las Directivas comunitarias otorgan a estas amplias facultades para establecer el régimen jurídico más adecuado en cada caso.

Así, el Considerando 6 de la Directiva sobre contratación Pública (Directiva 2014/24/UE) recuerda esa libertad de los Estados miembros para organizar en su territorio la prestación de los servicios sociales obligatorios, así como de cualquier otro servicio, ya sean servicios de interés económico general o servicios no económicos de interés general. Más adelante (Considerando 114), la propia norma precisa que en ese marco de libertad que corresponde a los Estados miembros, estos no necesariamente deben celebrar contratos públicos para la prestación de servicios a las personas (y, entre ellos, los servicios sociales), sino que pueden recurrir a otras fórmulas entre las que se menciona su mera financiación o la concesión de licencias o autorizaciones a todos los operadores económicos que cumplan las condiciones previamente fijadas por el poder adjudicador, sin límites ni cuotas, siempre que dicho sistema garantice una publicidad suficiente y se ajuste a los principios de transparencia y no discriminación. En los mismos términos se manifiestan la Directiva de concesiones (Directiva 2014/23/UE) en su Considerando 54 y la Directiva relativa a la contratación en los sectores excluidos (Directiva 2014/25/UE) en su Considerando 120.

Así pues, las Directivas habilitan ahora a los Estados miembros para que puedan concretar fórmulas específicas, ad hoc, distintas a las puramente contractuales para la prestación de los servicios sociales, entre ellas y $\sin$ carácter limitativo se mencionan las dos posibilidades indicadas. Por una parte, la financiación de esas actividades y, por otra, la habilitación a todos los terceros interesados (y debidamente autorizados por cumplir los requisitos establecidos con carácter general) en su realización.

Debe recordarse a este respecto, que las Directivas comunitarias no prejuzgan cuál es la naturaleza jurídica de la prestación ni quien realiza efectivamente el servicio, sino que lo determinante es la forma en que este se presta, se organiza y financia, pero, desde luego, su regulación alcanza también a los casos en los que estas actividades se configuran como auténticos servicios públicos. En consecuencia, y teniendo en cuenta la condición de servicios públicos en sentido estricto que corresponde a los servicios sociales incluidos en los Catálogos de los respectivos Sistemas Públicos de Servicios Sociales autonómicos, la mera financiación a la que alude la Directiva en su Considerando 114 solo podría referirse al fomento o subvención de actividades sociales de carácter privado por su interés público, esto es, esa posibilidad quedaría inserta en la actividad de fomento de la Administración.

En cambio, la segunda de las opciones (concesión de licencias o autorizaciones a todos los operadores económicos que cumplan las condiciones fijadas por un poder adjudicador) que se menciona en las Directivas sería viable para la gestión de las prestaciones sociales integradas en los Sistemas Públicos de Servicios Sociales. Es esta última posibilidad, precisamente la que sienta las bases del concierto social a que nos referimos.

Para este caso, las Directivas delimitan, como se ha indicado, determinadas características y condiciones que deberían concurrir para su compatibilidad con el Derecho comunitario. En primer lugar, la garantía de una publicidad suficiente y la sujeción del sistema a los principios de transparencia y no discriminación y, en

la Directiva a "los servicios sociales relativos a la vivienda social, la atención a los niños y el apoyo a familias y personas temporal o permanentemente necesitadas proporcionadas por el Estado, por prestadores encargados por el Estado o por asociaciones de beneficencia reconocidas como tales por el Estado". 
segundo lugar, además, la exigencia de que la opción de gestionar los servicios sociales (públicos) quede abierta a todos los operadores económicos interesados que cumplan las condiciones establecidas, sin límites ni cuotas de ningún tipo, previa obtención de las licencias o autorizaciones articuladas a tal efecto.

Este planteamiento se ha trasladado, prácticamente de manera literal, a la LCSP cuyo artículo 11.6 excluye del ámbito de aplicación de esta norma la "prestación de servicios sociales por entidades privadas, siempre que esta se realice sin necesidad de celebrar contratos públicos, a través, entre otros medios, de la simple financiación de estos servicios o la concesión de licencias o autorizaciones a todas las entidades que cumplan las condiciones previamente fijadas por el poder adjudicador, sin límites ni cuotas, y que dicho sistema garantice una publicidad suficiente y se ajuste a los principios de transparencia y no discriminación".

Resulta, pues, esencial para descartar la aplicabilidad de la LCSP que las fórmulas que se establezcan sobre la base del artículo 11.6 citado se garantice la libre concurrencia de cualquier sujeto interesado en la prestación de los servicios sociales de que se trate. Ello excluiría un elemento intrínsecamente vinculado al régimen de los contratos públicos $y$, por consiguiente, al concepto mismo de contrato en sentido europeo, como es el de la elección de una oferta y, por tanto, de un adjudicatario. Así lo ha entendido el Tribunal de Justicia de la Unión Europea en diversos pronunciamientos de los que, a su vez, se deriva que el hecho de que pueda exigirse el cumplimiento de unos determinados requisitos preestablecidos a los eventuales interesados no supone en sí mismo una selección, pues tales requisitos no se configuran como criterios de adjudicación sino como condiciones vinculadas a la apreciación de la aptitud de los interesados para ejecutar el servicio en cuestión ${ }^{(39)}$.
En este marco, la propia LCSP, en su disposición adicional cuadragésima novena, remite a las Comunidades Autónomas la posibilidad de adoptar las normas que sean necesarias para articular instrumentos no contractuales para la prestación de servicios públicos destinados a satisfacer necesidades de carácter social.

Tal previsión es completamente superflua $\mathrm{y}$, entendemos, viene simplemente a evidenciar la conveniencia de desarrollar esta posibilidad de gestión indirecta de servicios sociales como modo adecuado (más adecuado) de realizar este tipo de actividades, dado que no corresponde a la LCSP habilitar a las Comunidades Autónomas para adoptar dicha normativa ${ }^{(40)}$

Por una parte, porque tal y como ya se ha evidenciado, las fórmulas no contractuales de gestión de servicios sociales quedan excluidas del ámbito de aplicación de la LCSP, por lo que, no tratándose de la celebración de contratos no opera la competencia básica estatal al respecto. $Y$, además, porque corresponde a las Comunidades Autónoma la competencia exclusiva en materia de asistencia social de acuerdo con el artículo 148.1.20 $\mathrm{CE}^{(41)}$.

En consecuencia, es una competencia propia de las Comunidades Autónomas ordenar los servicios sociales en su territorio y organizar su prestación en los términos y con arreglo a los mecanismos que estimen más adecuados.

(39) En este sentido, la STJUE de 2 de junio de 2016, asunto C-410/14, Falk Pharma (ECLI:EU:C:2016:399), apartados 37 a 41, en relación con un procedimiento de participación convocado por la DAK (un seguro de enfermedad alemán) para la celebración de acuerdos de rebaja que tuviesen por objeto medicamentos cuyo principio activo fuese la mesalazina. En dicho procedimiento se preveía la participación de todas las empresas interesadas que cumpliesen los requisitos de admisión y la celebración con cada una de esas empresas de contratos idénticos, cuyas condiciones estaban preestablecidas y no eran negociables. En el mismo sentido la STJUE de 1 de marzo de 2018, asunto C-9/17, Tirkkonen (ECLI:EU:2018:142), apartados 33 a 37, cuyo objeto es una convocatoria de licitación publicada por la Agencia del espacio rural de Finlandia para la implementación de un programa de desarrollo en virtud de la cual se organizó un procedimiento de licitación con vistas a celebrar contratos de servicios de asesoramiento a favor de las explotaciones agrarias. A tal convocatoria podía concurrir cualquier asesor siempre que demostrara que estaba cualificado, recibía formación periódica y tenía experiencia como asesor en los ámbitos en los que pretendían asesorar. Véase sobre esta cuestión Domínguez, M. (2020). La acción concertada de los servicios a las personas en la ley de contratos del sector público y en la legislación autonómica: ¿instrumentos no contractuales para la prestación de servicios públicos destinados a satisfacer necesidades de carácter social? En L. Tolivar \& M. Cueto (dirs.), La prestación de servicios socio-sanitarios. Nuevo marco de la contratación pública (p. 52), Tirant lo Blanch.

(40) De igual manera lo entiende Serrano (2017, p. 131).

(41) Cabría aquí realizar un análisis teórico sobre la confluencia de los conceptos de asistencia social y servicios sociales, aunque en la práctica todas los Estatutos de Autonomía, bien por la vía del citado artículo 148.1.20 CE, bien por la vía del artículo 149.3 CE recogen las competencias exclusivas de las Comunidades Autónomas en los ámbitos de la asistencia social y de los servicios sociales. Habría que tener en cuenta, no obstante, las competencias que se reserva el Estado en relación con el Sistema de Autonomía y Atención a la Dependencia y con algunas otras cuestiones accesorias. 
Actualmente todas las Comunidades Autónomas han aprobado Leyes dirigidas a establecer el régimen de sus respectivos Sistemas de Servicios Sociales y a establecer, en concreto, las posibilidades de prestación de los servicios de las redes públicas, de manera que a las formas tradicionales, gestión directa por la propia Administración con sus propios medios o a través de entidades dependientes de ella y gestión indirecta a través de los contratos regulados en la LCSP, se añaden ahora los conciertos sociales ${ }^{(42)} y$, en algunas casos también, los convenios con entidades de iniciativa social.

El grado de regulación en las distintas normas es diverso, muy genérico en algunos casos, remitiendo a normas reglamentarias el futuro desarrollo de esta fórmula; mientras que, en otros, se ha podido desarrollar un marco normativo más preciso capaz de otorgar mayor seguridad jurídica a los diversos operadores ${ }^{(43)}$.

Estas normas reguladoras del concierto social (o de la acción concertada como se prefiere denominar por algunas Comunidades Autónomas) lo definen, con carácter general, en base a sus notas caracterizadoras; es decir, como mecanismo de carácter organizativo dirigido a la prestación de servicios sociales de titularidad o responsabilidad pública que utiliza para ello a entidades cuya financiación, acceso y control sean públicos y dirigidos a la satisfacción de objetivos sociales.

En todos los casos, el recurso a esta fórmula se sostiene sobre principios de solidaridad, igualdad, participación de las personas usuarias y promoción de la iniciativa social, pero también de otros directamente vinculados a la prestación, tales como la correcta atención a las especificidades y necesidades de los usuarios, arraigo de estos en su entorno social, calidad asistencial o atención continuada e integral de la persona.

El concierto se formaliza a través de acuerdos suscritos por la Administración titular o responsable del servicio y por la entidad concertada en los que se recogerán con exactitud todas las condiciones que se hubieran establecido, en particular, el contenido objetivo, subjetivo y temporal de la acción concertada, los derechos y obligaciones de cada parte en cuanto a la ejecución de la prestación del servicio, su régimen económico, el número de unidades concertadas y el resto de determinaciones que contribuyan a delimitar el alcance del concierto.

\section{La naturaleza del concierto social: fórmula organizativa para la gestión indirecta de servicios sociales públicos}

De acuerdo con el marco jurídico descrito, europeo y español, no cabe duda de que el concierto social se configura como una fórmula de gestión indirecta de servicios sociales públicos. Se ha defendido por algún sector doctrinal su configuración como una técnica de fomento que responde, bien a la naturaleza de convenio, bien a la de acto administrativo necesitado de aceptación ${ }^{(44)}$, si bien, en todo caso, dirigido a promover el desarrollo por los particulares interesados de actuaciones consideradas de interés público, pues se entiende que la entidad concertada actúa en paralelo a la Administración y no de manera subordinada a esta en el desarrollo de las actividades objeto de concierto y, además, que el destinatario de dicha actividad es la sociedad y no la Administración(45).

(42) Debe indicarse que incluso antes de que se aprobaran las Directivas comunitarias tres Comunidades Autónomas habían contemplado ya la posibilidad de celebrar conciertos de naturaleza no contractual para la gestión de sus servicios sociales. Es el caso del País Vasco, cuya Ley de Servicios Sociales, aprobada en el año 2008, incluyó un "régimen de concierto diferenciado de la modalidad contractual de concierto regulada en la normativa de contratación de las administraciones públicas" (artículo 61.1) y en el mismo sentido, Castilla y León, en su Ley 16/2010, de Servicios Sociales. Algo después, la Comunidad Autónoma de las Islas Baleares reformó en el año 2013 su Ley de Servicios Sociales para incluir la regulación expresa del concierto social.

(43) Se incluye un Anexo con la regulación existente sobre el concierto social en las distintas Comunidades Autónomas. No se menciona la Comunidad de Madrid, cuya Ley vigente de Servicios Sociales (Ley 11/2003, de 27 de marzo) no contempla este mecanismo. Se prepara una nueva Ley en la que sí se incluirá, si bien, a día de la fecha no se ha publicado un Proyecto.

(44) En el primer caso puede verse el estudio ya clásico de Salas, J. (1968). El régimen de la acción concertada. Revista de Administración Pública, 56, 435-482; en especial, 471, que configura esta técnica como un acuerdo de voluntades que determina la configuración de una relación de sujeción especial, todo ello en relación con los planes de desarrollo aprobados en España durante la década de los 60. En el mismo sentido, más recientemente, véase Manent Alonso \& Tenhaeff Lackschewitz (2018, pp. 213-220). En el segundo puede mencionarse a Gallego, A. (1980). La acción concertada: nuevas y viejas técnicas jurídicas de la Administración. Contribución a la distinción entre la resolución y el contrato administrativo. En Homenaje a J. Galván Escutia (pp. 191-260), Universidad de Valencia. A favor de su consideración como un modo de fomento administrativo véase Manent, L. (2017), La influencia del Tribunal de Justicia de la Unión Europea en la configuración de la acción concertada en los servicios sociales. Revista Valenciana d'Estudis Autonomics, 62, 294-295 y Gimeno Feliu (2018, p. 45).

(45) En este sentido véase Manent Alonso \& Tenhaeff Lackschewitz (2018, p. 220). 
A nuestro juicio, no obstante, ello no resulta ser correcto en atención al objeto y al alcance del concierto social. Desde luego ha sido y sigue siendo frecuente la concesión de subvenciones (medida de fomento por excelencia) en el ámbito de los servicios sociales para financiar proyectos o servicios, tanto en régimen de concurrencia competitiva como a través de convenios (subvenciones nominativas) ${ }^{(46)}$, pero la consecuencia, habitualmente, no es la prestación de servicios sociales públicos sino de servicios sociales no incorporados al Sistema ${ }^{(47)}$ y complementarios a este.

Ahora bien, la finalidad del concierto social es precisamente la realización de ciertas prestaciones propias de los Sistemas Públicos de Servicios Sociales, esto es, de servicios sociales públicos, de titularidad administrativa y que responden a la noción clásica de servicios públicos (y también al concepto comunitario de servicios de interés general en sus distintas acepciones, según lo explicado). No se pretende incentivar el desarrollo de actividades o iniciativas privadas en las que está presente un interés público, sino que el concierto aparece como una vía por la que se tratan de hacer efectivas actuaciones que vienen a satisfacer directamente necesidades de determinados ciudadanos que acceden al Sistema Público (prestaciones) y que se configuran como usuarios (uti singuli) del mismo.

Como ocurre en cualquier otro supuesto de gestión indirecta (contractual) la concurrencia de un tercero, de carácter privado, en la ecuación de la prestación de servicios de titularidad pública implica la aplicabilidad de normas de Derecho privado que, sin embargo, se circunscriben, normalmente, a los medios y recursos, materiales, personales y técnicos y su organización interna, pero sin alcanzar a la responsabilidad pública de la prestación que se traduce en un conjunto de reglas que informan el funcionamiento del servicio en sí mismo y en relación con el usuario, sustentadas siempre sobre un régimen de Derecho Público a respetar en todo caso por la entidad concertada. No cabe duda, así, de que cualquier servicio objeto de concertación debe ajustarse a los principios generales característicos de todos los servicios públicos, esto es, los principios de continuidad, igualdad, accesibilidad, asequibilidad o calidad, entre otros, además de, por supuesto, a las potestades de policía que corresponden a la Administración titular o responsable del servicio.

Las regulaciones autonómicas, no obstante, son dispares en cuanto a la calificación del concierto social como un mecanismo de gestión indirecta de servicios sociales públicos y prefieren encuadrar esta fórmula como una especie de tercera vía, junto a la gestión directa, por una parte, y la gestión indirecta de naturaleza contractual por otra ${ }^{(48)}$. No parece adecuada tal diversificación, puesto que, de acuerdo con lo que señalamos, independiente de su carácter no contractual, supone la prestación por un tercero y con medios de este, de un servicio de titularidad o responsabilidad pública ${ }^{(49)}$.

Debe advertirse, no obstante, que para el caso bastante excepcional de conciertos sociales celebrados con entidades públicas diferentes al sujeto concertante el vínculo resultante no determinaría un supuesto de gestión indirecta sino directa y articulada por las diversas vías admisibles de relación interadministrativa.

Por lo demás, y como se apunta, no se trata de un mecanismo contractual. Así se permite expresamente por las Directivas comunitarias, y en nuestro ordenamiento jurídico se ha concretado tanto desde la perspectiva de la contratación pública según hemos visto, como, sobre todo, desde la normativa de servicios sociales, en atención al tipo de actividad a la que se circunscriben estos conciertos, pero también a las condiciones sobre las que se sustentan,

(46) Como ejemplos recientes de tal régimen pueden mencionarse, por ejemplo, Real Decreto 681/2019, de 22 de noviembre, por el que se regula la concesión directa de subvenciones para el sostenimiento económico y financiero de la estructura central de determinadas entidades del Tercer Sector de Acción Social o Real Decreto-ley 33/2020, de 3 de noviembre, por el que se adoptan medidas urgentes de apoyo a entidades del Tercer Sector de Acción Social de ámbito estatal.

(47) No, al menos, a un Sistema Público de Servicios Sociales, sino al Sistema de Servicios Sociales que integra el conjunto de prestaciones de este tipo, independientemente de quien sea su prestador y en qué régimen.

48) Está claro su encaje entre las formas de gestión indirecta, por ejemplo, en la Ley 16/2019 de Servicios Sociales de Canarias (artículo 59). Sin embargo, son mayoría, las normas que diferencian al concierto como forma de prestación de servicios sociales públicos respecto a la gestión directa y la indirecta. Así ocurre, por ejemplo, en el caso de Aragón (artículo 2 de la Ley 11/2016), de Asturias (artículo 44 de la Ley 1/2003), de las Islas Baleares (artículo 89 de la Ley 4/2009), de Extremadura (artículo 19 de la Ley 14/015), de la Región de Murcia (artículo 7 bis de la Ley 3/2003) del País Vasco (artículo 60 de su Ley de Servicios Sociales), de La Rioja (artículo 61 de la Ley 7/2009) o de la Comunidad Valenciana (artículo 34 de la Ley 3/2019).

(49) Debe advertirse, no obstante, que para el caso bastante excepcional de conciertos sociales celebrados con entidades públicas diferentes al sujeto concertante el vínculo resultante no determinaría un supuesto de gestión indirecta sino directa y articulada por las diversas vías admisibles de relación interadministrativa. 
en particular, la posibilidad de que tales actividades o servicios, en sentido estricto y sin perjuicio de lo que se señalará más adelante, puedan ser desarrolladas por cualquier sujeto que reúna los requisitos exigidos y que cumpla con las exigencias formales establecidas, sin límites ni cuotas y, por tanto, sin procedimientos de selección y adjudicación ${ }^{(50)}$.

Ahora bien, las dificultades que se presentan en muchos casos para garantizar todas las exigencias y condiciones que conlleva el régimen del concierto social explican que en alguna ocasión se susciten dudas sobre la auténtica naturaleza de la figura que se regula o se vaya más allá de lo permitido para que el concierto social pueda mantenerse fuera de los márgenes de la normativa de contratos, lo que, sin duda, podría generar problemas en la aplicación práctica de este mecanismo.

Es el caso de Andalucía, cuya Ley de Servicios Sociales contempla el concierto social en sus artículos 101 y siguientes, este primer precepto lo define, en la línea de otras regulaciones autonómicas similares, como el instrumento por medio del cual se produce la prestación de servicios sociales de responsabilidad pública a través de entidades cuya financiación, acceso y control sean públicos. La Ley precisa posteriormente, en el apartado 3 de ese mismo precepto, que esta fórmula se establece como una modalidad diferenciada del concierto regulado en la normativa de contratación del sector público. Pues bien, aun cuando en el momento de aprobación de esta Ley aún estaba vigente la normativa de contratos anterior y por la tanto el concierto como como modalidad del contrato de gestión de servicios públicos ahora ya suprimido, no parece caber duda de que la pretensión del legislador andaluz no era únicamente la de diferenciar el concierto social del concierto como contrato, sino de excluir el concierto social de la propia regulación contractual. Tanto la sistemática que utiliza la Ley, dedicando un capítulo de su Título IV al concierto social y otro distinto a la participación de la iniciativa privada en el marco de la contratación del sector público, como el propio tratamiento que se hace del concierto social, alejado de las previsiones propias de la regulación de contratos, lo evidencian ${ }^{(51)}$.
El desarrollo de estas previsiones legales se hizo a través de una norma reglamentaria, el Decreto 41/2018. Su artículo 1 configura, sin embargo, el concierto social como un contrato administrativo especial de los previstos en la LCSP. Una completa alteración de la naturaleza jurídica inicialmente atribuida a esta figura y que resulta de las dudas de la Administración andaluza, cuyos servicios jurídicos recomendaron ajustarse en las normas reguladoras del concierto social al régimen de la normativa de contratos al no apreciar ninguna nota distintiva entre los contornos jurídicos de esta nueva fórmula y las figuras contractuales susceptibles de ser aplicadas. Posteriormente, el Consejo Consultivo de Andalucía ratificó ese planteamiento y salvó la eventual contradicción con lo establecido en la Ley estableciendo que el carácter diferenciado que se otorga al concierto social aludiría a una "especificación de la categoría contractual genérica", derivada de la singularidad que presentan los servicios sociales ${ }^{(52)}$.

Asimismo, pueden mencionarse las regulaciones de otras Comunidades Autónomas, especialmente de Aragón y del Principado de Asturias, aunque desde otra perspectiva distinta, pues en ambas Comunidades Autónomas se configura el concierto social (o la acción concertada como la denominan) como un instrumento no contractual. La duda que se plantea en relación con estas regulaciones es el procedimiento de selección de entidades que establecen para los casos en los que las limitaciones presupuestarias o el número y características de las prestaciones susceptibles de acción concertada lo hagan

(50) Recuérdese lo que establece a este respecto el artículo 11.6 LCSP y la jurisprudencia del TJUE analizada más arriba, en relación con la exigencia de concurrencia competitiva y selección de la mejor oferta para que pueda hablarse de contrato público en sentido estricto.

(51) De hecho, el artículo 17.4 de la Ley 4/2017, de 25 de septiembre, de los Derechos y la Atención a las Personas con Discapacidad en Andalucía establece que la "prestación del servicio de atención infantil temprana se podrá organizar a través de conciertos sociales, como modalidades diferenciadas de las recogidas en la normativa de contratación del sector público".

(52) Puede consultarse el expediente completo de tramitación del Decreto 41/2018 en https://www.juntadeandalucia.es/export/drupaljda/ Expediente\%20Decreto\%20concierto\%20social.pdf. Una crítica a este cambio puede verse en Nuñez, M. (2018). El concierto social para la prestación de los servicios sociales: Crónica de su reconducción a la legislación de contratos. Revista Andaluza de Administración Pública, 101, 495-506. Posteriormente, el Decreto 57/2020, de 22 de abril, por el que se regula el concierto social para la prestación de la Atención Infantil Temprana en Andalucía en desarrollo de lo establecido en la Ley 4/2017, sigue la misma tendencia de calificar el concierto social como un contrato administrativo especial. A este respecto véase Pizarro, R. (2020). El concierto social para la prestación de la Atención Infantil Temprana en Andalucía. Revista de Estudios de la Administración Local y Autonómica, 14, 88-103. 
necesario, estableciéndose a tal fin una serie de criterios de selección ${ }^{(53)}$. Esto es, se regula un procedimiento para elegir las entidades con las que concertar sobre la base de los criterios de selección previstos en las respectivas normas.

Esta previsión se opondría a los presupuestos sobre los que se sustenta el concierto social como fórmula no contractual, toda vez que la exclusión del ámbito de aplicación de la LCSP requeriría que cualquier entidad que cumpla los requisitos establecidos por el sujeto que concierta pudiera acceder al concierto. Así se pronunció también el Tribunal de Justicia de la Unión Europea en las Sentencias analizadas más arriba en las que, precisamente, se permite excluir la celebración de un contrato en los casos en los que no existe selección y, por tanto, adjudicación a un concreto licitador.

Es cierto que en buena parte de las normas autonómicas reguladoras del concierto social se hace referencia igualmente a la selección de las entidades y se establecen criterios con esa finalidad, si bien, pese a la confusión que ello puede conllevar, parece que tales previsiones aluden más bien a la selección a efectos de la asignación de las plazas o prestaciones objeto de concierto, esto es, a valorar el cumplimiento de los requisitos exigidos y a determinar el orden en el que se asignarán usuarios a las plazas concertadas, velando por la igualdad y la no discriminación entre las entidades concertadas, y no tanto a la selección de las entidades que pueden suscribirlo(54).
No parece que se trate, tampoco en estos últimos casos, de una redacción rigurosa y perfectamente acomodada a la esencia ( $y$ a la naturaleza) del concierto social, pero es fruto del modo, en que se ha implementado en nuestro país esta fórmula, más cercano al antiguo concierto (como modalidad del contrato de gestión de servicios públicos) que a una posibilidad de gestión indirecta abierta a cualquier entidad acreditada y autorizada para la realización de las prestaciones a concertar.

En -en nuestra opinión- un sistema puro, el concierto social debería permitir que los usuarios de un determinado Sistema Público de Servicios Sociales pudieran acceder libremente a las prestaciones concertadas de entre todas las posibilidades articuladas por la Administración titular o responsable del servicio, que, no obstante, debe ser la que en todo caso determine y prescriba la necesidad a cubrir(55). Alternativamente, podrían establecerse límites a esa decisión libre del usuario, en función de las características de la prestación de que se tratase. En el extremo

(53) Así se establece en el artículo 5 de la Ley aragonesa 11/2016 y en el artículo 8 de la Ley asturiana 3/2019. En ambos casos los criterios son sustancialmente análogos y se refieren a la implantación en la localidad donde vaya a prestarse el servicio, la experiencia que puedan acreditar, la valoración realizada por los usuarios respecto a sus servicios, las certificaciones de calidad obtenidas, la continuidad en la atención, el arraigo de las personas en el entorno de atención, las formación específica del equipo humano que prestará el servicio, establecimiento de mecanismos para la participación efectiva de los usuarios, etc.

(54) Puede advertirse claramente en los dos Decretos dictados en la Región de Murcia (el Decreto 10/2018 y el Decreto 62/2019). En ambos casos, se permite la presentación de solicitudes, en cualquier momento, por parte de los interesados en acceder a la concertación social, de manera que tras su verificación y de reunir los requisitos para ello, serán declaradas aptas para la concertación. Se prevén a tal fin diversos criterios para la asignación de cada concierto social. Un supuesto especial puede ser el de Galicia, cuyo Decreto 229/2020 establece dos procedimientos de concertación distintos, el de asignación de conciertos y la articulación de conciertos de adhesión. En el primer caso y de acuerdo con el artículo 9.2 de esta norma se trata de seleccionar a los prestadores de los servicios y el número de plazas, las prestaciones o programas que cada uno de ellos prestará durante el concierto social, de acuerdo con los criterios de selección y preferencia de la convocatoria. Será el procedimiento a emplear cuando sea preciso realizar una selección de las entidades concertantes en función de las limitaciones presupuestarias o del número y características de las prestaciones susceptibles de concierto social. En cambio, en los conciertos de adhesión las entidades que tengan la autorización o cumplan con el régimen de control al que estén sometidas o, en su caso, cuenten con la acreditación requerida y cumplan los requisitos de admisión, podrán adherirse al sistema durante toda la vigencia del concierto social.

(55) En este sistema puro en el que, una vez prescrita la prestación por la Administración, el usuario pudiera dirigirse a cualquier recurso del Sistema Público, podría entrar en juego el denominado cheque-servicio, con lo que se transformaría una prestación material en una prestación económica de carácter personal y finalista. En nuestro ordenamiento jurídico el cheque-servicio se asimila a lo previsto en el artículo 17 de la Ley 39/2006, de Promoción de la Autonomía Personal y Atención a las personas en situación de dependencia, aunque únicamente para aquellos supuestos en los que no pueda accederse a una prestación del Sistema Público de Servicios Sociales. En cambio, algunas Leyes de Servicios Sociales autonómicas lo contemplan con carácter general. La regulación sobre el concierto social dispone, normalmente, el abono contra factura por la Administración concertante a la entidad concertada a la vista de las prestaciones efectivamente realizas. Es el mecanismo que se ha implantado, por ejemplo, en las Islas Baleares (artículo 25 del Decreto 48/2017 de Baleares), en Galicia (artículo 39 del Decreto 220/2020) en la Región de Murcia (artículo 190 del Decreto 10/2018) y el que se prevé en el Proyecto de Decreto regulador de la concertación social en Castilla y León, véase en https://www.jcyl.es/junta/cp/P_DECRETO_REGIMEN_JURIDICO_DEL_CONCIERTO_SOCIAL_EN_CASTILLA_Y_LEON.pdf. No obstante, la mayoría de las Comunidades Autónomas no ha establecido el mecanismo de abono. A lo sumo se establece el modo de cálculo de las cantidades que deben pagarse a las entidades concertadas, remitiendo en muchas ocasiones a lo establecido en las bases de la convocatoria de concierto. 
opuesto, sería la Administración la competente para asignar usuarios a las concretas plazas y servicios concertados, sin ninguna posibilidad de decisión a cargo del usuario.

Las normas autonómicas han implantado, en rigor, un sistema en el que se toma en consideración prevalentemente la posición de las entidades concertadas para la asignación de usuarios antes que la libertad de elección de estos, combinando a lo sumo, ambos intereses, en una posición más o menos intermedia En esta se tienen en cuenta los criterios de selección a los que nos venimos refiriendo(56).

Algunas Comunidades Autónomas, por último, han previsto procedimientos de adjudicación directa de los conciertos sociales, sin publicidad ni concurrencia. Es el caso de Cataluña que lo permite cuando concurran unas concretas circunstancias que recuerdan a algunas de las que justifican, en el marco de la contratación pública, el recurso a un procedimiento negociado. También se prevé así en Extremadura, cuya norma reguladora del concierto social permite la utilización de esta vía, entre otros casos, "en los mismos supuestos que los previstos por la normativa de contratación pública” y, en términos prácticamente análogos, en la Comunidad Foral de Navarra ${ }^{(57)}$. Tal posibilidad viene a desvirtuar notablemente la esencia del concierto social y la exigencia de que se articule en base a una publicidad suficiente y de acuerdo a los principios de transparencia y no discriminación.

En cualquier caso y pese a las dudas y problemas jurídicos que se suscitan, técnicamente no puede dudarse de que nos encontramos ante una forma de colaboración público-privada que se traduce en la gestión indirecta de los servicios sociales públicos concertados, aunque no por la vía contractual tradicional. Probablemente será necesario introducir modificaciones en la regulación actual para ir acomodando el concierto social a su correcto objeto y perfilar adecuadamente sus contornos de manera que pueda ser un mecanismo eficaz y eficiente desde el punto de vista económico y social, permita satisfacer las necesidades para las que se ha establecido y resulte plenamente respetuoso con el resto del ordenamiento jurídico.

Por el momento los eventuales problemas que pueda implicar la implementación de esta figura en los términos en los que se configura por las Leyes autonómicas no ha generado mayor litigiosidad, salvo las quejas de entidades de carácter mercantil frente a la reserva absoluta a favor de las entidades sin ánimo de lucro que se realiza por algunas Leyes autonómicas, de acuerdo con lo que señalaremos a continuación. No es descartable que desde esa misma perspectiva mercantil se vaya más allá respecto a concretas disposiciones que resultan controvertidas en los términos que venimos señalando.

\section{La reserva o preferencia de las entidades de iniciativa social en la celebración de los conciertos sociales: ventajas y problemas jurídicos}

En el ámbito de los servicios sociales resulta característica, en términos generales, pero particularmente y por lo que aquí interesa, a efectos de encomendar a un sujeto del sector privado su gestión indirecta, una diferencia de partida, la que existe entre las entidades de iniciativa social y las de carácter mercantil. Son las primeras $y$, en concreto, las entidades sin ánimo de lucro, las que de forma mayoritaria van a actuar como entidades concertadas a través del mecanismo que se analiza, ahora bien, también se admite en algunas normas autonómicas que puedan concurrir a los conciertos sociales entidades públicas. En ambos casos se suscitan importantes dudas.

Por lo que se refiere a las entidades de iniciativa social no resulta fácil su identificación dada la diversidad de fórmulas jurídicas que

(56) Criterios tales como el arraigo de la persona en el entorno de atención, la implantación de las entidades concertadas en la localidad donde vaya a prestarse el servicio, responsabilidad social de la entidad concertada, lista de espera o demanda para acceso a los servicios, así como cualquier otro que permita valorar la capacidad y la idoneidad de las entidades prestadoras. La libertad de elección suele ser otro de los criterios que contemplan alguna de las normas autonómicas para su valoración conjunta con el resto de los mencionados, aunque en el caso de Galicia (artículo 3 del Decreto 229/2020) y de la Región de Murcia (artículo 8 del Decreto 10/2018) deberá atenderse, siempre que sea posible, prioritariamente a la libre elección de los usuarios. Otras normas no toman en consideración, en absoluto, ni siquiera como criterio a tener en cuenta, la posibilidad de elección del usuario. Es el caso, por ejemplo, de Aragón, de Extremadura, del País Vasco, de La Rioja, de la Comunidad Valenciana o de Castilla y León.

(57) Así véase el artículo 16 del Decreto 69/2020, que regula el concierto social en Cataluña. También en el artículo 8 de la Ley 13/2018 de Extremadura y en el artículo 5.1 de la Ley Foral 13/2017. En el caso de Asturias, la Ley 13/2019 prevé en su artículo 22 la posibilidad de celebrar acuerdos directos de acción concertada cuando concurran razones de urgencia, singularidad del servicio o carácter innovador del mismo. Esta Ley exige, no obstante, que se garantice, también en estos casos, los principios de publicidad y transparencia. 
pueden revestir y su muy distinto alcance y objetivos, quedando incluidas en el concepto en todo caso las entidades del tercer sector de acción social y, solo cuando carezcan de ánimo de lucro, también las entidades de economía social, pues estas últimas, si bien no responden a la lógica de funcionamiento de las entidades mercantiles, realizan una actividad económica sujeta en términos generales a las reglas y principios del mercado y la competencia, lo que difuminaría la imprescindible ausencia de ánimo de lucro ${ }^{(58)}$. Este es el planteamiento que ha acogido recientemente el Tribunal de Justicia de la Unión Europea al definir a las entidades sin ánimo de lucro como "organizaciones o asociaciones que tienen como objetivo desempeñar funciones sociales, carecen de finalidad comercial y reinvierten los eventuales beneficios con el fin de alcanzar el objetivo de la organización o asociación"(59).

Pese a esa confusión terminológica que, en algunos casos, concurren ${ }^{(60)}$ estas entidades de iniciativa social se están viendo reforzadas en las Leyes de Servicios Sociales de última generación, puesto que es frecuente que sean declaradas de interés general $y$, como consecuencia de ello, queden colocadas en una posición de preeminencia respecto al resto de entidades (con ánimo de lucro)(61). Incluso, desde la perspectiva estatal, se consideró pertinente otorgarles una especial consideración jurídica como entidades del tercer sector colaboradoras con las administraciones públicas, una nueva categoría dirigida a permitir el reconocimiento como colaboradoras en la ejecución de políticas públicas a un amplio elenco de organizaciones de carácter privado surgidas de la iniciativa ciudadana, sin ánimo de lucro y con fines de interés general, cualquiera que sea su forma jurídica ${ }^{(62)}$.

Más aún, ese peso específico que se les otorga a las entidades de iniciativa social se ha traducido, en las Leyes de Servicios Sociales autonómicas, en previsiones de prioridad o prevalencia, cuando no de exclusividad, para integrarse en las redes de servicios sociales públicas y contribuir a la prestación de los servicios incluidos en ellas

(58) Las entidades del tercer sector de acción social, tal y como se delimitan por la Ley 43/2015 (artículo 2), son organizaciones de carácter privado que surgen de la iniciativa ciudadana o social y que responden a criterios de solidaridad y de participación social, que persiguen fines de interés general y que carecen de ánimo de lucro. Su objetivo es impulsar el reconocimiento y el ejercicio de los derechos civiles, así como de los derechos económicos, sociales o culturales de las personas y grupos que sufren condiciones de vulnerabilidad o que se encuentran en riesgo de exclusión social. En su mayoría adoptan la forma de asociaciones y también, aunque en menor medida, de fundaciones. Por su parte, las entidades de economía social, en los términos de la Ley 5/2011 (artículos 4 y 5), son organizaciones en las que se otorga primacía a las personas y al fin social sobre el capital, y cuya gestión debe ser autónoma y transparente, democrática y participativa y, en todo caso, independiente de los poderes públicos. Al igual que las anteriores promueven valores de solidaridad, igualdad y cohesión social, si bien una de sus notas distintivas respecto a las entidades del tercer sector de acción social es la de que los resultados obtenidos como consecuencia de su actividad económica son aplicados en función del trabajo aportado y servicio o actividad realizada por las socias y socios o por sus miembros y, en su caso, al fin social objeto de la entidad. Es habitual que adopten la forma de cooperativas y sociedades laborales, así como de empresas de inserción y centros especiales de empleo. En menor medida de fundaciones y asociaciones que lleven a cabo actividad económica. En consecuencia, si bien las entidades de economía social encajarían en el concepto de entidades de iniciativa social, no todas se configuran como entidades sin ánimo de lucro. Véase sobre esta distinción en la que no podemos detenernos, entre otros, Pérez, M. (2015). El Tercer Sector: economía social y entidades no lucrativas. En C. Torres (edit.). España 2015. Situación social (pp. 888-900). CIS; y Argudo, J. (2002). El Tercer Sector y Economía Social Marco teórico y situación actual. Acciones e Investigaciones Sociales, 15, $239-263$.

(59) Véase la STJUE de 21 de marzo de 2019, asunto C-465/17, Falk Rettungsdienste (ECLI:EU:C:2019:234), que además diferencia estas entidades de aquellas organizaciones que son propiedad de su personal o en las que el personal participe directamente en la dirección, idea que responde, más bien a la noción de economía social, según se ha indicado.

(60) De manera puramente ejemplificativa puede apreciarse como la Ley 9/2016 de Servicios Sociales de Andalucía identifica a las entidades de iniciativa social con entidades sin ánimo de lucro, incluyendo expresamente a "las sociedades cooperativas calificadas como entidades sin ánimo de lucro" (artículo 3.7). Posteriormente, la misma Ley, cuando se refiere a la provisión de servicios del Sistema Público de Servicios Sociales alude, al referirse a la gestión tanto a través de conciertos como de contratos, a "las entidades de la iniciativa social, de economía social, cooperativas y pequeñas y medianas empresas" (artículo 100.4). En el caso de la Región de Murcia, su Ley de Servicios Sociales configura las entidades de iniciativa social a partir de la ausencia de ánimo de lucro, sin embargo, al regular lo criterios para la asignación de conciertos sociales en el ámbito de la protección de menores (Decreto 62/2019), se valora que las entidades concertadas sean entidades de economía social [artículo 8.1.e)].

(61) Algunas normas autonómicas (por ejemplo, de Andalucía, Asturias, Cataluña o Galicia) contemplan la posibilidad de declarar a las entidades de iniciativa social como entidades de interés general o social, lo que se traduce habitualmente en la preferencia en la concesión de subvenciones y ayudas relativas a servicios sociales, sin perjuicio de lo que a continuación se dirá respecto a la participación en conciertos sociales.

(62) En este sentido, la Exposición de motivos del Real Decreto-Ley $7 / 2013$, de 28 de junio. El artículo 4 de esta norma recoge las características que deben reunir este tipo de sujetos para alcanzar la categoría de "entidades del tercer sector colaboradoras con la Administración Pública". 
por alguna de las fórmulas habilitadas al efecto, en detrimento de la iniciativa privada de carácter mercantil. Es absolutamente evidente en el caso de los conciertos sociales ${ }^{(63)}$.

Este planteamiento, que resulta lógico en atención a la finalidad de las prestaciones y de las características que revisten los beneficiarios o usuarios de los servicios sociales así como del paralelo rechazo que supone la búsqueda de lucro económico en la vulnerabilidad de los más desfavorecidos, podría resultar incompatible con los principios de igualdad de trato y no discriminación, publicidad y transparencia que informan nuestro ordenamiento jurídico y que tienen su presupuesto básico en los artículos 49 y 56 TFUE. No obstante, desde el ámbito comunitario el propio Tribunal de Justicia admitió tempranamente la posibilidad de dar preferencia o reservar la prestación de servicios de interés general a entidades de iniciativa social, si bien de manera condicionada ${ }^{(64)}$. Por una parte, dicha posibilidad se ha concretado en una actividad asistencial dirigida a quienes se encuentran en una situación de necesidad y cuya prestación se sostiene sobre los principios de solidaridad, universalidad, eficiencia económica y eficacia y equilibrio presupuestario, constitutivos todos ellos de razones imperiosas de interés general que excluyen las reglas de competencia y libre prestación de servicios.

Por otra parte, las entidades de carácter social (principalmente, a las que se alude en las Sentencias, entidades de voluntariado) a las que se prioriza o reserva la prestación de los servicios de que se trata, deben insertarse necesariamente en esa finalidad social aludida, sin posibilidad de obtener beneficios como consecuencia de la realización de tales actividades (ni proporcionar ningún beneficio a sus miembros), aunque sí resulta posible que se les reembolsen los costes variables, fijos y permanentes necesarios para suministrarlas. Deben ser, pues, entidades sin ánimo de lucro en sentido estricto $^{(65)}$. Pero, además, la actividad que despliegan en estos ámbitos (mediante los conciertos o, en su caso, contratos con la Administración) debe tener un carácter marginal en el conjunto de los fines y cometidos que cumplen según su propia naturaleza.

Por último, las actividades concretas realizadas por estas entidades deben desarrollarse por trabajadores solo dentro de los límites necesarios para su normal desenvolvimiento, debiendo ajustarse necesariamente en su funcionamiento a las normas internas reguladoras de este tipo de organizaciones. Esto conlleva, por tanto, una importante actividad de voluntariado.

En definitiva, es posible excluir a determinados operadores económicos (entidades con ánimo de lucro) de la realización de prestaciones de carácter social, solo y exclusivamente cuando concurran todas las condiciones identificadas por el Tribunal de Justicia de la Unión Europea. Ahora bien, no existe ninguna previsión normativa comunitaria que establezca esa exclusión, por lo que la privación de participación de las entidades mercantiles en los conciertos sociales no tiene un carácter general y, mucho menos, al margen de los estrictos requisitos y límites establecidos por la jurisprudencia comunitaria.

En todo caso, y como deriva de la doctrina sentada por el Tribunal de Justicia de la Unión Europea, es necesario un marco jurídico que delimite todas las circunstancias objetivas que excluyen las reglas de competencia y libre prestación de servicios y que justifique la consecución de los objetivos de solidaridad propios de los fines sociales que tratan de satisfacerse, así como la plena eficiencia presupuestaria que permita el equilibrio económico del sistema(66). Ese cometido

(63) Tal planteamiento se recoge igualmente en la Ley 43/2015, del Tercer Sector de Acción Social que insta al Gobierno a promover mecanismos de colaboración con estas entidades, prestando especial atención al uso de los conciertos y convenios.

(64) En una primera sentencia de 17 de junio de 1997 (asunto Sodemare) a la que ya se ha aludido más arriba, se resolvió sobre la compatibilidad con el entonces TCE y las reglas sobre competencia en él recogidas de diversas disposiciones aprobadas en la región de Lombardía (Italia) que restringían a operadores privados sin ánimo de lucro la posibilidad de suscribir conciertos para la prestación de servicios de asistencia social de carácter sanitario encuadrados dentro del Sistema de Seguridad Social y remunerados por las autoridades públicas en cuanto a los costes que generan. En una segunda Sentencia de 11 de diciembre de 2014, asunto, C-113/13, Azienda sanitaria locale n.5 «Spezzino» (ECLI:EU:C:2014:2440), se planteó dicha compatibilidad respecto del transporte sanitario de urgencia y de extrema urgencia y con la encomienda que se hace de estas prestaciones por las normas de la región italiana de Liguria a organizaciones de voluntariado y a la Cruz Roja italiana. Más recientemente la Sentencia de 28 de enero de 2016, asunto C-50/14, Consorcio Artigiano Servizio Taxi e Autonoleggio (CASTA) (ECLI:EU:C:2016:56), se pronunció sobre la adjudicación, sin licitación, por parte de la Agencia sanitaria local de tres localidades del Piamonte italiano, del servicio de transporte de personas en tratamiento de diálisis a diferentes centros sanitarios, a la Associazione Croce Bianca del Canaveses y a otras asociaciones de voluntariado.

(65) En este sentido véase el apartado 60 de la STJUE de 21 de marzo de 2019, ya citada.

(66) Véase sobre los límites a la prioridad de las entidades de iniciativa social en este ámbito, Villar, F. (2005, p. 406), Vaquer Caballería, M. (2002, pp. 237-238) y Bernal, M. A. (2006). La incidencia de la contratación pública en la gestión de los servicios sociales. Revista 
corresponde en nuestro caso, en los términos que se vienen señalando, a las normas de las Comunidades Autónomas en materia social y asistencial. En este sentido son mayoritarias las regulaciones que contemplan la prioridad para la concertación a favor de las entidades de iniciativa social, cuando existan análogas condiciones de eficacia, calidad y rentabilidad social respecto a otros eventuales interesados (con ánimo de lucro) (67). No obstante, en algunas Comunidades Autónomas el concierto se circunscribe únicamente a este tipo de entidades, con exclusión de cualquier otro sujeto(68).

Solo en un caso se establece un régimen mixto, disponiéndose la exclusividad a favor de las entidades del tercer sector social salvo cuando los conciertos afecten a servicios sociales declarados de interés económico general, en cuyo caso, podrán concurrir a ellos también entidades con ánimo de lucro, aunque en esos supuestos se reconoce la prioridad de las entidades del tercer sector ante similares condiciones de eficacia, calidad y costes, así como de eficacia presupuestaria ${ }^{(69)}$.

En ninguno de estos supuestos, sin embargo, se presta especial atención a los motivos que permiten la preferencia o reserva, que se circunscribe al hecho de que la prestación concertada se realice por entidades sin ánimo de lucro $^{(70)}$. Esto es, se atiende a la pura naturaleza subjetiva de las entidades concertadas, sin prestar

Aragonesa de Administración Pública, 29, 223-224; y Álvarez, M. (2015). La colaboración privada en la gestión de servicios sociales públicos. La incidencia de las nuevas directivas de contratación y su transposición al ordenamiento jurídico español. Revista Española de Derecho Administrativo, 172, 357. Más recientemente, en relación con el concierto social y desde la perspectiva de la Ley de garantía de la unidad de mercado Garrido, A. (2017). Las nuevas formas de gestión de los servicios sociales: elementos para un debate. Revista Catalana de Dret Públic, 55, 84-100. También, véase Gimeno Feliu, J. (2016). Un paso firme en la construcción de una contratación pública socialmente responsable mediante colaboración con entidades sin ánimo de lucro en prestaciones sociales y sanitarias. En Observatorio de Contratación Pública, http://www.obcp.es/opiniones/un-paso-firme-en-la-construccionde-una-contratacion-publica-socialmente-responsable analiza la aplicación de la jurisprudencia comunitaria. En relación con las prestaciones públicas sanitarias, pone en duda la posibilidad de concluir conciertos sociales Villar, F. (2020). Los modelos de gestión de los servicios sanitarios en España. En A. Agulló (dir.), Financiación de la Sanidad. Tributación, Gestión, Control del Gasto y Reparto Constitucional del Poder Financiero (pp. 226-227), Tirant lo Blanch, precisamente porque estas prestaciones no están ordenadas sobre la base de los principios de solidaridad y eficacia presupuestaria, a diferencia de los que ocurre con el sistema público de seguridad social.

(67) Es el caso de Andalucía (artículo 101.1 de la Ley 9/2016), de Cataluña (disposición adicional tercera, apartado 4 del Decreto-Ley 3/2016), del País Vasco (artículo 65.1 Ley 12/2018) y de La Rioja (artículo 61.3 de la Ley 7/2009). En el caso de la Región de Murcia la prioridad es doble. Por una parte, se otorga prioridad para la suscripción de conciertos sociales a las entidades privadas con o sin ánimo de lucro que sean declaradas de interés asistencial de acuerdo con lo establecido en el artículo 7 de la Ley $3 / 2003$ de Servicios Sociales (artículo 7 bis de esta Ley). Por otra parte, también serán prioritarias para la concertación las entidades sin ánimo de lucro que atiendan a personas de condición socioeconómica desfavorable, y ello cuando concurran análogas condiciones de eficacia, calidad y costes (artículo 25.3 de la Ley 3/2003). Es el caso también de Castilla-La Macha (artículo 42 de su Ley 14/2010), si bien en esta Comunidad Autónoma, la prioridad a favor de las entidades de iniciativa social se formula genéricamente, tanto para los supuestos de concierto, como de convenio o contrato, y sin supeditar dicha prioridad a la existencia de una igualdad de condiciones con la iniciativa privada de naturaleza mercantil. De hecho, el proyecto de Reglamento que se prepara para desarrollar el régimen del concierto social en Castilla-La Mancha, incluye dentro de las entidades concertadas, tanto a las de iniciativa social como a las de carácter mercantil. Véase en https://www.castillalamancha.es/gobierno/bienestarsocial/actuaciones/proyecto-de-decretopor-el-que-se-regula-el-concierto-social-para-la-gesti\%C3\%B3n-de-servicios-sociales y. Por su parte, la Ley 13/2008 de Servicios Sociales de Galicia no establece ninguna limitación o condicionamiento para la celebración de conciertos sociales, sin embargo, el Reglamento de desarrollo de la Ley aprobado por el Decreto 229/2020, sí otorga prioridad a las entidades de iniciativa social cuando existan análogas condiciones de efectividad, calidad y rentabilidad social y aclara, no obstante, que "siempre que, en todo caso, se garantice la libre concurrencia y se respeten los principios de igualdad de trato, de no discriminación y de transparencia" (artículo 13).

(68) Así ocurre en Aragón, de acuerdo con lo previsto en el artículo 2.c) de la Ley 11/2016 que modificó lo previsto inicialmente en su Ley $5 / 2019$, de Servicios Sociales, que preveía únicamente la prioridad de este tipo de entidades. Exactamente en el mismo sentido se recoge ahora en el artículo 44.1.c) de la Ley $1 / 2003$ de Servicios Sociales de Asturias, de conformidad con lo previsto en la Ley $3 / 2019$, que determinó el cambio desde la prioridad inicial a la exclusividad actual a favor de las entidades de iniciativa social. También se reserva la posibilidad de celebrar conciertos a las entidades sin ánimo de lucro en Extremadura, según lo establecido en el artículo 5.1.a) de la Ley extremeña 1/2018, en Navarra en atención a lo dispuesto en el artículo 1.1 de su Ley Foral 13/2017 y en la Comunidad Valenciana, de acuerdo con el artículo 87.1 de su Ley 3/2019. Así se establece también en el caso de Canarias (artículo 65.1 de la Ley 16/2019), pese a que esta misma Ley, con carácter general, para la gestión indirecta de los servicios sociales dispone la preferencia de las entidades de iniciativa social cuando existan análogas condiciones de eficacia, calidad y rentabilidad social.

(69) Véase los artículos 2.1, 5.2 y 6.4 de la Ley $12 / 2018$ de las Islas Baleares.

(70) Véase Díez Sastre, S. (2020). La acción concertada como nueva forma de gestión de los servicios sanitarios. En Agulló, A. (dir.), Financiación de la Sanidad. Tributación, Gestión, Control del Gasto y Reparto Constitucional del Poder Financiero (pp. 236-237), 
demasiada atención, en la mayoría de los casos, al resto de condicionamientos y límites requeridos para que este modo de actuación sea compatible con el Derecho comunitario, en especial, la verificación del carácter plenamente solidario de estas entidades, la retribución que obtienen o la eficacia presupuestaria que implica el recurso a estas entidades ${ }^{(71)}$.

Además, y sin perjuicio de cuanto se ha dicho, será esencial a la hora de concretar la conformidad a Derecho de las preferencias y reservas articuladas a favor de las entidades de iniciativa social, la determinación de la actividad de que se trate, pues de servicios sociales económicos, será difícil justificar la exclusión de la iniciativa privada de carácter mercantil ${ }^{(72)}$.

En efecto, al margen de los servicios sociales no económicos, un buen número de prestaciones sociales tienen el carácter de actividades económicas que, por lo tanto, deben quedar sujetas a los principios generales de competencia, no discriminación, transparencia y proporcionalidad y ya no tanto desde la perspectiva de la contratación pública sino, primordialmente, desde las propia de las reglas del mercado interior. Como hemos visto ya, en este último caso el hecho de que la actividad se califique de social o que sea realizada por un sujeto sin ánimo de lucro no es en sí mismo suficiente para eludir la calificación de actividad económica, sujetándose por lo tanto a los principios y normas comunitarias correspondientes. Por lo tanto, en esos supuestos la restricción del concierto social únicamente a las entidades de iniciativa social sería difícilmente conciliable con el Derecho comunitario ${ }^{(73)}$.

No obstante, nuevamente, esta circunstancia no se ha apreciado de manera correcta por todas las Comunidades Autónomas, pues muchas de ellas no contemplan tal precisión a la hora de establecer el catálogo de servicios susceptibles de ser prestados mediante concierto social.

En definitiva, la absoluta exclusión de entidades de carácter mercantil en la realización de determinadas prestaciones

Tirant lo Blanch, considera que este principio de solidaridad "no parece tratarse de una cláusula general que permita dar prioridad de forma general a entes sin ánimo de lucro. Tampoco se trata de la solidaridad que está intrínsecamente asociada al concepto de servicio público. Debe existir un claro arraigo del sistema de prestación de servicios en el principio de solidaridad". Respecto a la eficacia, véase Gimeno Feliu, J. (2016). Reglas básicas para mejorar la eficiencia y la transparencia en la contratación pública. Presupuesto y Gasto Público, 82(139), considera que la eficacia en estos casos debe quedar justificada no solo desde presupuestos exclusivamente economicistas, sino que tiene que valorarse la conexión entre este principio y el de consecución de los fines y objetivos, en este caso, sociales, perseguidos.

(71) Véase la STSJ de la Comunidad Valenciana núm. 560/2018 de 12 junio, (Sala de lo Contencioso-Administrativo, Sección $5^{a}$. Rec. núm. 236/2017. ECLI:ES:TSJCV:2018:2468). Esta Sentencia, si bien se pronuncia sobre la acción concertada en el ámbito sanitario y desestima el recurso contencioso-administrativo interpuesto por una Unión Temporal de Empresas frente a la Orden 3/2017, de 1 de marzo de la Conselleria de Sanidad Universal y Salud Pública, que regula la acción concertada para la prestación de servicios a las personas en el ámbito sanitario, no obstante, establece importantes precisiones sobre esta cuestión. Se impugnaba por la actora su exclusión de la acción concertada y la falta de justificación por la Administración conforme a lo establecido en el TJUE de esa exclusión. En la resolución judicial se entiende que, efectivamente, la Orden no contiene ninguna mención justificativa del cumplimiento de las exigencias establecidas por la jurisprudencia de la Unión y que debería preverse, en el curso del procedimiento de concertación la verificación de tales requisitos y límites. No obstante, entiende que ello no determina necesariamente la nulidad de la Orden, pues sí se mencionan en su articulado los principios de solidaridad y eficiencia presupuestaria por lo que, se concluye, deberían ser los concretos acuerdos de acción concertada los que de manera ineludible justificasen y demostrasen todas las circunstancias que hacen posible la exclusión de la concurrencia de entidades mercantiles. Véase también la STSJ de la Comunidad de Aragón núm. 269/2020, de 17 de junio de 2020 (Sala de lo contencioso-Administrativo. Sección 1ª Recurso núm. 43/2018. ECLI:ES:TSJAR:2020:598), que sí anula la Orden CDS/2042/2017, de 30 de noviembre, por la que se regulaba la acción concertada en materia de prestación de servicios sociales en Aragón, impugnada por una Asociación de empresas de asistencia a domicilio, por carecer de una memoria económica suficiente, considerando insuficiente la justificación de la Administración que señaló que al ser realizadas las prestaciones por entidades sin ánimo de lucro solo se retribuían los costes variables y fijos de la prestación o el servicio, excluyendo el beneficio industrial, por lo que la aplicación del Reglamento en todo caso supondría una aplicación más eficiente de los recursos públicos. No obstante, como afirma la Sentencia, ello no resulta ser cierto en absoluto pues como se evidencia, las tarifas por servicio abonadas a las entidades sin ánimo de lucro son las mismas que las previstas para la contratación pública.

(72) Como se ha indicado ya, ese es el planteamiento de la Ley 12/2018 de las Islas Baleares, en la que se establece (artículo 5.2) la necesidad de que se identifiquen los servicios de interés económico general entre los que pueden ser objeto de acción concertada, señalando respecto a ellos que "podrán suscribir conciertos todas las personas físicas o jurídicas de carácter privado, con o sin ánimo de lucro, sea cual sea la forma jurídica que adopten".

(73) Véase Gimeno, J. (2018, pp. 32-34), donde insiste en la necesidad de tener en cuenta el principio de prohibición de abuso de Derecho para impedir prácticas abusivas de las asociaciones de voluntariado o de sus miembros, señalando que "una regla de 'preferencia' no puede extenderse como regla general en la prestación de estos servicios, pues se quebraría la exigencia del debido respeto a los equilibrios como garantía de la adecuada prestación del servicio público". 


\section{Referencias bibliográficas}

concierto social, presenta notables dudas hasta el punto de que recientemente se ha planteado una cuestión prejudicial ante el Tribunal de Justicia de la Unión Europea dirigida a verificar la compatibilidad con las normas y principios comunitarios de la regulación implantada en la Comunidad Valenciana, y donde se cuestiona principalmente si resulta legítimo excluir a las entidades sin ánimo de lucro para la prestación de toda clase de servicios sociales, cualquiera que sea su valor estimado y a cambio del mero reembolso de los costes, a través de un mecanismo no contractual como es el concierto social ${ }^{(74)}$.

Para terminar, y como se indicó más arriba, el concierto social puede concluirse en algún caso también con entidades públicas ${ }^{(75)}$. En estos casos, las normas autonómicas que así lo prevén no concretan si debe tratarse de entidades públicas sin ánimo de lucro aunque parece lógico que así sea, pues de lo contrario se habilitaría la participación de entidades mercantiles públicas, pero no privadas, con clara discriminación de estas últimas.

En estos casos, por lo demás, se plantea una duda jurídica que va más allá de la propia naturaleza y régimen jurídico del concierto en sentido estricto, toda vez que con su celebración se entabla un vínculo jurídico entre dos entidades públicas, la Administración concertante por una parte y la entidad pública concertada por otra, que debe remitirse al ámbito de las relaciones interadministrativas y, por lo tanto, a su regulación. En consecuencia, deberán integrarse el tratamiento de estos conciertos sociales tanto desde la perspectiva organizativa ( $y$, por tanto, teniendo en cuenta la regulación estatal básica sobre el régimen jurídico de las Administraciones Públicas) como desde la material, representada por la normativa sectorial autonómica ${ }^{(76)}$.

En definitiva, aún quedan pendiente una delimitación más precisa de todo el sistema que sustenta los conciertos sociales que, sin duda, irá produciéndose en sucesivas reformas normativas que, en muchos casos, tendrán como base la jurisprudencia de nuestros tribunales y del Tribunal de Justicia de la Unión Europea.
Aguado i Cudolà, V. (2012). El régimen jurídico de las prestaciones de los servicios sociales. En A. Ezquerra (coord.), El marco jurídico de los servicios sociales en España (pp. 47-86). Atelier.

Alemán, C. \& Alonso, J. (2011). Los sistemas de servicios sociales en las Leyes autonómicas de servicios sociales. Revista General de Derecho Administrativo, 27.

Alonso, J. \& Alemán, C. (2020). El sistema de servicios sociales. Nuevas tendencias en España. Tirant lo Blanch.

Alonso, J. \& Gonzalo, B. (2000). La asistencia social y los servicios sociales en España (2. ${ }^{a}$ ed.), Boletín Oficial del Estado.

Álvarez, M. (2004). El abastecimiento de agua en España. Thomson-Civitas.

Álvarez M. (2015). La colaboración privada en la gestión de servicios sociales públicos. La incidencia de las nuevas directivas de contratación y su transposición al ordenamiento jurídico español. Revista Española de Derecho Administrativo, 172, 317-362.

Beltrán, J. (1992). El régimen jurídico de la acción social pública. Instituto Vasco de Administración Pública.

Bernal, M. (2006). La incidencia de la contratación pública en la gestión de los servicios sociales. Revista Aragonesa de Administración Pública, 29, 205-236.

Bernal, M. (2018). La contratación de los servicios a las personas. En E. Gamero \& I. Gallego, Tratado de Contratos del Sector Público (pp. 2792-2824). Tirant lo Blanch.

Chinchilla, M. (1991). El servicio público ¿una amenaza o una garantía para los derechos fundamentales? Reflexiones sobre el caso de la televisión. (coord.), Estudios sobre la Constitución

(74) La cuestión prejudicial se acuerda en virtud del Auto de la Sala de lo Contencioso-Administrativo del Tribunal Superior de Justicia de la Comunidad Valenciana de 30 de julio de 2020 (ECLI:ES:TSJCV:2020:74A) y se suscita en el marco del recurso contenciosoadministrativo interpuesto por la Asociación Estatal de Entidades de Asistencia a Domicilio frente a determinados preceptos del Decreto 181/2017, de 17 de noviembre de 2017, por el que se desarrolla la acción concertada para la prestación de servicios sociales en el ámbito de la Comunidad Valenciana por unidades de iniciativa social. Puede consultarse en el DOUE núm. C 423/28, de 7 de diciembre de 2020.

(75) Lo prevén, por ejemplo, la Ley aragonesa 11/2016 y también se contempla en el borrador que se prepara en Castilla-La Mancha en desarrollo de lo previsto en su Ley 14/2010.

(76) Véase a este respecto las reflexiones de Díez Sastre, S. (2020, pp. 244-245), que se plantea también la relación que se entablaría en estos casos entre la entidad concertante y la concertada de considerar la naturaleza contractual de los conciertos sociales. 
Española. Homenaje al Profesor Eduardo García de Enterría (pp. 943-972). Civitas.

De la Cuétara, J. (1993). La actividad de la Administración. Tecnos.

De Palma del Teso, A. (2009). Los servicios sociales en Cataluña como marco de atención a las situaciones de dependencia. En Aguado i Cudolà, V. (Coord.), Servicios Sociales, dependencia y derechos de la ciudadanía. Atelier.

Decreto-ley $3 / 2016$, de 31 de mayo, de medidas urgentes en materia de contratación pública. Cataluña. Boletín Oficial de Estado, 188, de 5 de agosto de 2016. https://www.boe.es/buscar/pdf/2016/BOE-A2016-7564-consolidado.pdf

Decreto 48/2017, de 27 de octubre, por el que se establecen los principios generales a los que han de someterse los conciertos sociales. Islas Baleares. Boletín Oficial de Estado, 294, de 06 de diciembre de 2018. https://www.boe.es/buscar/pdf/2018/BOE-A-201816678-consolidado.pdf

Decreto 181/2017, de 17 de noviembre, de desarrollo de la acción concertada para la prestación de servicios sociales en el ámbito de la Comunitat Valenciana por entidades de iniciativa social. Comunidad Valenciana. Diari Oficial de la Generalitat Valenciana, 8197, de 23 de noviembre de 2017, 48245-48266. http://dogv.gva.es/datos/2017/12/23/ pdf/2017_11941.pdf

Decreto 10/2018, de 14 de febrero, por el que se establece el régimen jurídico de los conciertos sociales en la Región de Murcia en los servicios sociales especializados en los sectores de personas mayores y personas con discapacidad. Murcia. Boletín Oficial de la Región de Murcia, 49, de 28 de febrero de 2018, 5023-5040. https://www.carm.es/web/ pagina? IDCONTENIDO $=142588 \& I D T I P O=60 \& R A S T R O=c 891 \$ \mathrm{~m}$ $5806,5808,58$

Decreto 41/2018, de 20 de febrero, por el que se regula el concierto social para la prestación de los servicios sociales. Andalucía. Boletín Nacional de la Junta de Andalucía, 39, de 23 de febrero de 2019. https://www.juntadeandalucia.es/boja/2018/39/4

Decreto 62/2019, de 3 de mayo, por el que se establece el régimen jurídico de los conciertos sociales en la Región de Murcia, en materia de protección y reforma del menor. Murcia. Boletín Oficial de la Región de Murcia, 105, de 9 de febrero de 2019. http://www.carm.es/web/ pagina? IDCONTENIDO $=155458 \&$ IDTIPO $=60 \&$ RASTRO $=c 891 \$ \mathrm{~m}$ $5806,5808,6066$

Decreto 69/2020, de 14 de julio, de acreditación, concierto social y gestión delegada en la Red de Servicios Sociales de Atención Pública. Cataluña. DOGC, 8178, de 16 de julio de 2020.

Decreto 229/2020, de 17 de diciembre, por el que se desarrolla el régimen de conciertos sociales en el ámbito de la Comunidad Autónoma de Galicia. Galicia. DOG, 3, de 7 de enero de 2021.

Díez-Picazo, L. (2009). Los servicios de interés económico general en el ordenamiento comunitario. En Muñoz Machado, S. \& Esteve Parado, J., (dir.), Derecho de la regulación económica. I. Fundamentos e instituciones de la regulación (p. 409). lustel.

Díez Sastre, S. (2020). La acción concertada como nueva forma de gestión de los servicios sanitarios. En A. Agulló (dir.), Financiación de la Sanidad. Tributación, Gestión, Control del Gasto y Reparto Constitucional del Poder Financiero (pp. 231261). Tirant lo Blanch.
Domínguez, M. (2019). Los contratos de prestación de servicios a las personas. Repensando las formas de gestión de los servicios sanitarios públicos tras las Directivas de contratos de 2014 y la Ley 9/2017 de Contratos del Sector Público, Revista General de Derecho Administrativo, 50.

Domínguez, M. (2020). La acción concertada de los servicios a las personas en la ley de contratos del sector público y en la legislación autonómica: ¿instrumentos no contractuales para la prestación de servicios públicos destinados a satisfacer necesidades de carácter social?. En L. Tolivar \& M. Cueto (dirs.), La prestación de servicios sociosanitarios. Nuevo marco de la contratación pública (pp. 47-76). Tirant lo Blanch.

Gallego, A. (1980). La acción concertada: nuevas y viejas técnicas jurídicas de la Administración. Contribución a la distinción entre la resolución y el contrato administrativo. En Homenaje a J. Galván Escutia (pp. 191-260). Universidad de Valencia.

Garrido, A. (2017). Las nuevas formas de gestión de los servicios sociales: elementos para un debate. Revista Catalana de Dret Públic, 55, 84 100. http://dx.doi.org/10.2436/rcdp.i55.2017.3007.

Garrido, A. (2020). Los servicios sociales en el s. XXI. Nuevas tipologías y nuevas formas de prestación. Aranzadi.

Gimeno, J. (2016). Reglas básicas para mejorar la eficiencia y la transparencia en la contratación pública. Presupuesto y Gasto Público, 82, 137-158.

Gimeno, J. (2018). La colaboración públicoprivada en el ámbito de los servicios sociales y sanitarios dirigidos a las personas. Condicionantes europeos y constitucionales. Revista Aragonesa de Administración Pública, 52, 12-65.

Gómez-Ferrer, R. (1973). El régimen general de los Centros privados de enseñanza. Revista de Administración Pública, 70, 7-27.

Hernández, F. (2018). La delimitación de los contratos públicos de servicios y de concesión de servicios. En Gimeno, J. (dir.), Estudio sistemático de la Ley de Contratos del Sector Público (pp. 477515). Thomson Reuters Aranzadi.

Huergo. A. (2018). El riesgo operacional en la nueva Ley de Contratos del Sector Público. En M. Vaquer, A. Moreno \& A. Descalzo (coords.), Estudios de Derecho Público en homenaje a Luciano Parejo Alfonso (pp. 1791-1832). Tirant lo Blanch.

Laguna de Paz, J. (2007). Servicios de interés económico general. Civitas-Thomson-Reuter.

Laguna de Paz, J. (2016). Los servicios de interés general en la Unión Europea. Derecho PUCP, 76, 19-50. https://doi.org/10.18800/ derechopucp.201601.001. 
Ley $1 / 2003$, de 24 de febrero, de servicios sociales. Asturias. Boletín Oficial de Estado,86, de abril de 2003. https://www.boe.es/buscar/ pdf/2003/BOE-A-2003-7404-consolidado.pdf

Ley $3 / 2003$, de 10 de abril, del Sistema de Servicios Sociales. Murcia. Boletín Oficial de Estado, 35, de 10 de febrero de 2004, 5792-5803. ttps://www.boe.es/boe/dias/2004/02/10/pdfs/A05792-05803.pdf

Ley 2/2007, de 27 de marzo, de Derechos y Servicios Sociales. Cantabria. Boletín Oficial de Estado, 94, de 19 de abril de 2007. https:// www.boe.es/buscar/pdf/2007/BOE-A-2007-8186-consolidado.pdf

Ley $13 / 2008$, de 3 de diciembre, de Servicios Sociales. Galicia. Boletín Oficial de Estado, 15, de 17 de enero de 2009, 5513-5553. https://www. boe.es/boe/dias/2009/01/17/pdfs/BOE-A-2009-807.pdf

Ley $12 / 2008$, de 5 de diciembre, de Servicios Sociales. País Vasco. Boletín Oficial de Estado, 242, de 7 de octubre de 2011, 105335-105396. https://www.boe.es/boe/dias/2011/10/07/pdfs/BOE-A-2011-15726.pdf

Ley 4/2009, de 11 de junio, de Servicios Sociales. Islas Baleares. Boletín Oficial de Estado, 163, de 7 de julio de 2009, 56578-56640. https://www.boe.es/boe/dias/2009/07/07/pdfs/BOE-A-2009-11186.pdf

Ley $5 / 2009$, de 30 de junio, de Servicios Sociales. Aragón. Boletín Oficial de Estado, 201, de 20 de agosto de 2009, 71537-71584. https:// www.boe.es/boe/dias/2009/08/20/pdfs/BOE-A-2009-13689.pdf

Ley $7 / 2009$, de 22 de diciembre, de Servicios Sociales. La Rioja. Boletín Oficial de Estado, 14, de 16 de enero de 2010, 3808-3852. https://www. boe.es/boe/dias/2010/01/16/pdfs/BOE-A-2010-658.pdf

Ley 14/2010, de 16 de diciembre, de Servicios Sociales. Castilla - La Macha. Boletín Oficial de Estado, 38, de 14 de febrero de 2011, 15496-15540. https://www.boe.es/boe/dias/2011/02/14/pdfs/ BOE-A-2011-2752.pdf

Ley $16 / 2010$, de 20 de diciembre, de Servicios Sociales. Castila y León. Boletín Oficial de Estado, 7, de 8 de enero de 2011, 1756-1803. https://www.boe.es/boe/dias/2011/01/08/pdfs/BOE-A-2011-402.pdf

Ley 14/2015, de 9 de abril, de Servicios Sociales. Extremadura. Boletín Oficial de Estado, 108, de 6 de mayo de 2015, 39626-39664. https:// www.boe.es/boe/dias/2015/05/06/pdfs/BOE-A-2015-5017.pdf

Ley 11/2016, de 15 de diciembre, de acción concertada para la prestación a las personas de servicios de carácter social y sanitario. Aragón. Boletín Oficial de Estado, 14, de 17 de enero de 2017. https:// www.boe.es/buscar/pdf/2017/BOE-A-2017-491-consolidado.pdf

Ley 9/2016, de 27 de diciembre, de Servicios Sociales. Andalucía. Boletín Oficial de Estado, 18, de 21 de enero de 2017, 5415-5487. https://www.boe.es/boe/dias/2017/01/21/pdfs/BOE-A-2017-657.pdf

Ley $12 / 2018$, de 15 de noviembre, de servicios a las personas en el ámbito social de la Comunidad Autónoma de las Illes Balears. Islas Baleares. Boletín Oficial de Estado, 294, de 6 de diciembre de 2018. https://www.boe.es/buscar/pdf/2018/BOE-A-2018-16678-consolidado. pdf

Ley 13/2018, de 26 de diciembre, de conciertos sociales para la prestación de servicios a las personas en los ámbitos social, sanitario y sociosanitario de Extremadura. Extremadura. Boletín Oficial de Estado, 35, de 9 de febrero de 2019, 12603-12618. https://www.boe. es/boe/dias/2019/02/09/pdfs/BOE-A-2019-1792.pdf

Ley $3 / 2019$, de 18 de febrero, de servicios sociales inclusivos. Comunidad Valenciana. Boletín Oficial de Estado, 61, de 12 de marzo de 2019, 23249-23349. https://www.boe.es/boe/ dias/2019/03/12/pdfs/BOE-A-2019-3489.pdf

Ley $3 / 2019$, de 15 de marzo, sobre acción concertada con entidades de iniciativa social sin ánimo de lucro para la prestación de servicios de carácter social. Asturias. Boletín Oficial de Estado, 108, de 6 de mayo de 2019, 48023-48039. https://www.boe.es/boe/dias/2019/05/06/pdfs/ BOE-A-2019-6662.pdf

Ley 16/2019, de 2 de mayo, de Servicios Sociales. Canarias. Boletín Oficial de Estado, 141, de 13 de junio de 2019, 61699-61773. https://www.boe.es/ boe/dias/2019/06/13/pdfs/BOE-A-2019-8794.pdf

Ley Foral 13/2017, de 16 de noviembre, de conciertos sociales en los ámbitos de salud y servicios sociales. Navarra. Boletín Oficial de Estado, 310, de 22 de diciembre de 2017. https:// www.boe.es/buscar/pdf/2017/BOE-A-2017-15290consolidado.pdf

Malaret, E. (2002). Administración pública y servicios públicos: la creación de una red de servicios sociales a los ancianos en la transformación del Estado de Bienestar. En J. Tornos (coord.), Los servicios sociales de atención a la tercera edad: el caso de Cataluña (pp. 265332). Tirant lo Blanch.

Malaret, E. (2003). Servicio público, actividad económica y competencia. - ¿Presenta especificidades la esfera local?. Revista de Estudios de la Administración Local. 291, 567-608. https://doi.org/10.24965/reala.vi291.9190

Manent, L. (2017). La influencia del Tribunal de Justicia de la Unión Europea en la configuración de la acción concertada en los servicios sociales. Revista Valenciana d'Estudis Autonomics, 62.

Manent, I. \& Tenhaeff, S. (2018). Tipología de contratos (iii): los contratos para la gestión de servicios públicos. En J. Mestre (dir.), Ley de Contratos del Sector Público: Ley 9/2017, de 8 de noviembre: aspectos novedosos (pp. 185-220). Tirant lo Blanch.

Martín, R. (1967). Guía de actividades públicas asistenciales. La asistencia social como servicio público. Ministerio de la Gobernación.

Míguez, L. (2012). La transformación del régimen jurídico de los servicios sociales. Revista Española de Derecho Administrativo, 153, 33-62.

Moreno, M. (2002). Régimen jurídico de la asistencia social. Ministerio de Trabajo y Asuntos Sociales.

Muñoz, S. (1998). Servicio público y mercado. Civitas.

Nuñez, M. (2018). El concierto social para la prestación de los servicios sociales: Crónica de su 
reconducción a la legislación de contratos. Revista Andaluza de Administración Pública, 101. 495-506. https://doi.org/10.46735/raap.n101.725

Palomar, A. (2008). El sistema integral de promoción de la autonomía personal y atención a las personas en situación de dependencia. Competencias. En A. Sempere \& P. Charro (coords.), Comentario sistemático a la Ley de Dependencia. Ley 39/2006, de 14 de diciembre, de Promoción de la Autonomía Personal y Atención a las Personas en Situación de Dependencia. Thomson-Aranzadi.

Parejo, L. (2004). Servicios públicos y servicios de interés general: la renovada actualidad de los primeros. Revista de Derecho de la Unión Europea, 7, 51-68.

Pérez, M. (2015). El Tercer Sector: economía social y entidades no lucrativas. En C. Torres (ed.), Situación social (pp. 888-900). CIS.

Pizarro, R. (2020). El concierto social para la prestación de la Atención Infantil Temprana en Andalucía. Revista de Estudios de la Administración Local y Autonómica, 14, 88-103. https://doi. org/10.24965/reala.i14.10861

Rodríguez de Santiago, J. (2007). La Administración del Estado Social. Marcial Pons.
Salas, J. (1968). El régimen de la acción concertada. Revista de Administración Pública, 56 , 435-482.

Serrano, J. (2017). La contratación de servicios sociales en las Directivas de contratación pública y su transposición en el Proyecto de Ley de Contratos del Sector Público. Revista Aranzadi Unión Europea, 10, 129-143.

Souvirón Morenilla, J.M. (1998). La actividad de la Administración y el servicio público. Comares.

Tornos, J. \& Galán, A. (2005). Los problemas de la contraposición entre económico y social en la doctrina europea de los servicios de interés general. Revista General de Derecho Administrativo, 8.

Tornos, J. \& Galán, A. (2007). La configuración de los servicios sociales como servicio público. Derecho subjetivo de los ciudadanos a la prestación del servicio. Ministerio de Trabajo y Asuntos Sociales.

Tornos, J. \& Galán, A. (2010). De nuevo sobre la doctrina europea de los servicios de interés general: los problemas para definir la familia de los "servicios sociales" y su aplicación en materia de vivienda. Revista General de Derecho Administrativo, 25.

Vaquer, M. (2010). De nuevo sobre la "doctrina europea de los servicios de interés general: los problemas para definir la familia de los servicios sociales" y su aplicación en materia de vivienda. Revista General de Derecho Administrativo, 25.

Villar, F. (2020). Los modelos de gestión de los servicios sanitarios en España. En A. Agulló (dir.), Financiación de la Sanidad. Tributación, Gestión, Control del Gasto y Reparto Constitucional del Poder Financiero (pp. 198-229). Tirant lo Blanch. 
